\title{
Rotating Disk Apparatus: Types, Developments and Future Applications
}

\author{
Musaab K. Rashed ${ }^{1,2}$, Hayder A. Abdulbari ${ }^{3}$, Mohamad Amran Mohd Salleh ${ }^{1,4} \&$ M. Halim Shah Ismail ${ }^{1}$ \\ ${ }^{1}$ Department of Chemical and Environmental Engineering, Faculty of Engineering, Universiti Putra Malaysia, \\ Malaysia \\ ${ }^{2}$ Institute of technology, Middle Technical University, Foundation of technical education, Iraq \\ ${ }^{3}$ Center of Excellence for Advanced Research in Fluid Flow, Universiti Malaysia Pahang, Malaysia \\ ${ }^{4}$ Material and Processing Technology Laboratory, Institute of Advanced Technology, Universiti Putra Malaysia, \\ Malaysia \\ Correspondence: Hayder A. Abdulbari, Center of Excellence for Advanced Research in Fluid Flow, Universiti \\ Malaysia Pahang, Gambang, 26300, Kuantan, Pahang, Malaysia. E-mail: hayder.bari@gmail.com/ \\ asalleh@upm.edu.my
}

Received: April 25, 2016

Accepted: May 5, 2016

Online Published: June 22, 2016

doi:10.5539/mas.v10n8p198

URL: http://dx.doi.org/10.5539/mas.v10n8p198

\begin{abstract}
Power consumption reduction investigations attracted the attention of enormous numbers of researchers in the past few decades due to its high academic and economic impacts. The pumping power losses during the transportation of crude oils are considered as one of the main power consuming applications due to the turbulent mode of transportation. Investigating the possible solutions for this problem is expensive and time consuming due to the large apparatuses needed to simulate the flow in real pipelines. Rotating disk apparatus (RDA) is an instrument mainly comprising a rotating disk and an electrical motor to rotate the disk, which was implemented as an efficient and economical path to simulate what can be done in pipelines through generating a controlled degree of turbulence. This technique was also used in many other scientific applications due to its dynamic mode of operation. For example, a rotating disk electrode was used in electrodeposition processes and to characterize deposition film thickness and uniformity. The rotating disk reactor was employed to investigate the reaction rate between fluids and solid surfaces. The present work evaluates the RDA from different prospective and applications in order to introduce it as an efficient research tools for future dynamic investigations.
\end{abstract}

Keywords: rotating disk apparatus, drag reduction, rotating disk electrode, rotating disk reactor

\section{Introduction}

In industry and research many types of rotating disk apparatus have been used, which can be classified and named depending on their use and application. For example, the rotating disk electrode apparatus can be used in electrodeposition processes and characterizes film uniform and thickness. The rotating disk instrument is increasingly being applied in the laboratory to study the reaction between fluids and solid surfaces. It is widely used in the petroleum industry for kinetic studies of the reaction of acidic fluids and chelating agents with reactive rock (Boomer, Mccune \& Fogler, 1972; Fredd \& Fogler, 1998; K. Lund, Fogler \& Mccune, 1973; K. Lund \& Foglers, 1975). In addition, it is employed to examine the effects of different additives on the drag reduction performance of liquids. The rotating disk apparatus (RDA) used in drag reduction applications is an equipment for simulating external flow, which includes the flow over flat plates, as well as the flow around submerged objects and is used for turbulent drag reduction characterization (Tong, Goldburg, Huang \& Witten, 1990).

Although the drag reduction mechanism has been the focus of significant research, reportedly no comprehensive and sufficient explanation has been found (Armstrong \& Jhon, 1984; Cadot, Bonn \& Douady, 1998; Gyr \& Bewersdorff, 1995; Jhon, Sekhon \& Armstrong, 1987; Tabor \& Gennes, 2007). Several attempts can be found in the literature to introduce different techniques to reduce the energy dissipation in pipelines. Generally, these techniques can be classified into two major categories, namely: passive and active (Abdulbari, Yunus, Abdurahman \& Charles, 2013; Hwang, Kwon \& Cho, 2008). 
Methods which do not need any additives are called passive methods, such as oscillating and wavy walls (Jung, 1992), riblets and dimples for which more than $10 \%$ drag reduction has been reported (Abdulbari et al., 2013; Bandyopadhyay, 1986; Baron, Quadrio \& Vigevano, 1993; Jung, 1992), and micro bubbles, also introduced as passive methods to improve the flow in channels (McCORMICK \& Bhattacharyya, 1973; Wu, Ouyang \& Shiah, 2008), and around $60 \%$ drag reduction has been reported by compliant surfaces in this category (Gad-El-Hak, 1998; Kramer, 1960).

The first and typical response for drag reduction is introduced by active methods involving the operation of an amount of an additive or drag reducing agent (DRA) inside the fluid, which has been reported by many scientists due to its economical and academic effect (Abdulbari, Shabirin \& Abdurrahman, 2013). Moreover, because of the great influence of additives in conserving energy, the knowledge of drag reduction has been given attention for both its educational and industrial relevance ( A. Al-Sarkhi, Abu-Nada \& Batayneh, 2006; A. Al-Sarkhi \& Hanratty, 2001, 2002; Al-sarkhi, Nakla \& Ahmed, 2011; A. Al-Sarkhi, 2010; Dujmovich \& Gallegos, 2005; Jhon, Sekhon \& Armstrong, 1987; Moussa \& Tiu, 1994; Rehage , Wunderlich \& Hoffmann, 1986; Shikata, Hirata \& Kotaka, 1988; Virk, 1975).

Looking at the literature, it is obvious that in active methods most researchers have adopted pipe flows to examine the turbulent drag reduction that produces a pressure-driven flow in a channel. In 1930 (Forest \& G.Grierson, 1931), investigating a turbulent channel flow, detected a decrease in the loss of energy from timber paste fibre suspensions in water, and later, in 1949, (K. J. Mysels, 1949) stated that aluminium di-soap markedly decreased the skin friction of gasoline in a tube. (Toms, 1949) reported more than $80 \%$ reduction in the turbulent skin friction of mono-chlorobenzene by adding only $0.25 \%$ polymethylmethacrylate (a long chain hydrocarbon), the discovery of which led to the first identification of polymers as DRA.

Recently, a number of studies have analysed the drag reduction of a flow by additives through other techniques; such as a cylindrical double gap rheometer device (Kalashnikov, 1998), coaxial cylinders (Bizotto \& Sabadini, 2008; Nakken, Tande \& Elgsaeter, 2001) and rotating disk apparatus (RDA) (Burger, Munk \& Wahl, 1982; H. J. Choi, Kim, Sohn \& Jhon, 2000; Forest \& G.Grierson, 1931; K. J. Mysels, 1949; Peyser \& Little, 1971; Wu, Ouyang \& Shiah, 2008). Rotational apparatus has gained attention for determining the drag reduction and mechanical shear degradation of polymers because of the difficulties and time consumed in analysing the degradation in pipe systems (H. J. Choi \& Jhon, 1996; J. Hoyt, 1972; C. A. Kim et al., 1997; C. A. Kim, Choi, Kim, \& Jhon, 1998; C. A. Kim et al., 1999; Yang, Choi, Kim \& Jhon, 1991).

The flow surrounding a rotating disk is very important, mainly in connection with revolving apparatuses. Furthermore, when the disk, which is rotating in the flow, which is called friction flow, without forced pressure gradients, the source in the turbulent boundary layer, is altered and this is important when compared with pressure-driven flow events, since most of the DR happens only in the turbulent region. In other words, the drag reduction event is associated only with the frictional portion, and creating a friction assessment device, which is as precise but less huge, is of specific interest. Consequently, for the study of total drag reduction, the rotating disk scheme is approved (Ge, Zhang \& Zakin, 2007; C. H. Hong, Choi \& Kim, 2008; C. A. Kim, Jo, Choi, C. B. Kim \& Jhon, 2000; Sohn, Kim, Choi \& Jhon, 2001).

One of the factors which can characterise the turbulent flow is a dimensionless quantity, the Reynolds number $\left(\mathrm{NR}_{\mathrm{e}}\right)$, which is the proportion of inertial forces to viscous forces, and is defined as (Schlichting, 1979): $\mathrm{NR}_{\mathrm{e}}$ $=\rho \omega \mathrm{r}^{2} / \mu$, where $\rho$ is fluid density, $\omega$ is angular velocity $[2 \pi$ (revolutions per minute) $/ 60 \mathrm{rad} / \mathrm{s}], \mathrm{r}$ is the radius of the disk and $\mu$ is fluid viscosity [Pa.s]. In RDA, when the $\mathrm{NR}_{\mathrm{e}}$ reaches a critical value of $3 \times 10^{5}$, the flow becomes turbulent. Also, it is important to know that RDA is increasingly being employed in the laboratory for investigating the reaction rate between fluids and solid surfaces (D. Boomer et al., 1972; Litt \& Serad, 1964; Mumick, Welch, Salazar \& McCormick, 1994). Since the temperature mechanism is steadier than other drag reduction measurement apparatus, RDA is appropriate for assessing the drag reduction under fixed temperature situations.

The motivation for writing this paper is the wide range of application of RDA in industry and the emerging benefits of using this instrument to compare it with other apparatus in terms of the difficult and time-consuming analysis of degradation. In this study, rotating disk apparatus types and their application will be illustrated in three aspects: reactor, electrode, and drag reduction.

\section{Rotating Disk Apparatus Applications}

Rotating disk apparatus (RDA) is widely used in different industries and has many applications. Some types of RDA are named according to their application such as rotating disk electrode apparatus, rotating ring disk electrode apparatus, and rotating disk reactor (or spinning disk reactor). However, the most common application 
of RDA is to use it in drag reduction investigations. Most of the previous work on drag reduction using RDA has involved investigating the effects of adding numerous types of additives (e.g., polymers, surfactants, and complex mixtures of polymers and surfactants) on the drag reduction performance. This section includes a brief description of the common applications of rotating disk apparatus.

\subsection{Rotating Disk Electrode Apparatus}

One of the rotating disk electrode types is the rotating ring disk electrode (RRDE-3A), shown in Figure 1. This instrument is a constant rotation system used in hydrodynamic modulation rotating ring disk electrochemistry. It comprises an electrode with $7 \mathrm{~mm}$ diameter and a short stainless steel shaft delivers for a miniature and concentric circle electrode system, which is capable of highly accurate rotation and modulation. This apparatus has been designed for laboratory application, and is a compact and computerized rotating electrode system with a rotating velocity range of 100-8000 rpm. The ring electrode and disk electrode can be used as the working electrode simultaneously. RRDE is an extremely powerful and well established method for studying complex chemical and electrochemical reactions in aqueous and nonaqueous solvents at ambient temperatures. The working electrode, main motor shaft unit, and glass cell are simple to replace. Spin coating can be easily done because the motor position and the normal rotation function can be reversed. Figure 2 shows a photograph of typical high temperature Au-Mo RRDE (Stojanovic, Kubacki, Dorin \& Frazer, 1995).

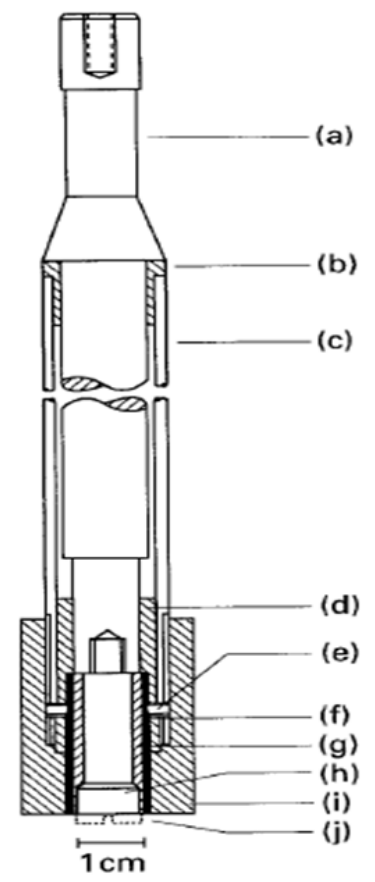

Figure 1. A schematic diagram of the rotating ring-disc electrode: (a) internal Inconel shaft/rotator connection, (b) glass-filled Teflon bush, (c) outer Inconel tube, (d) boron nitride support, (e) stainless steel screws, (f) gold tube,

(g) boron nitride gap insulator, (h) molybdenum rod, (i) outer boron nitride insulating sheath and (j) slotted end-piece. (Stojanovic et al., 1995) 

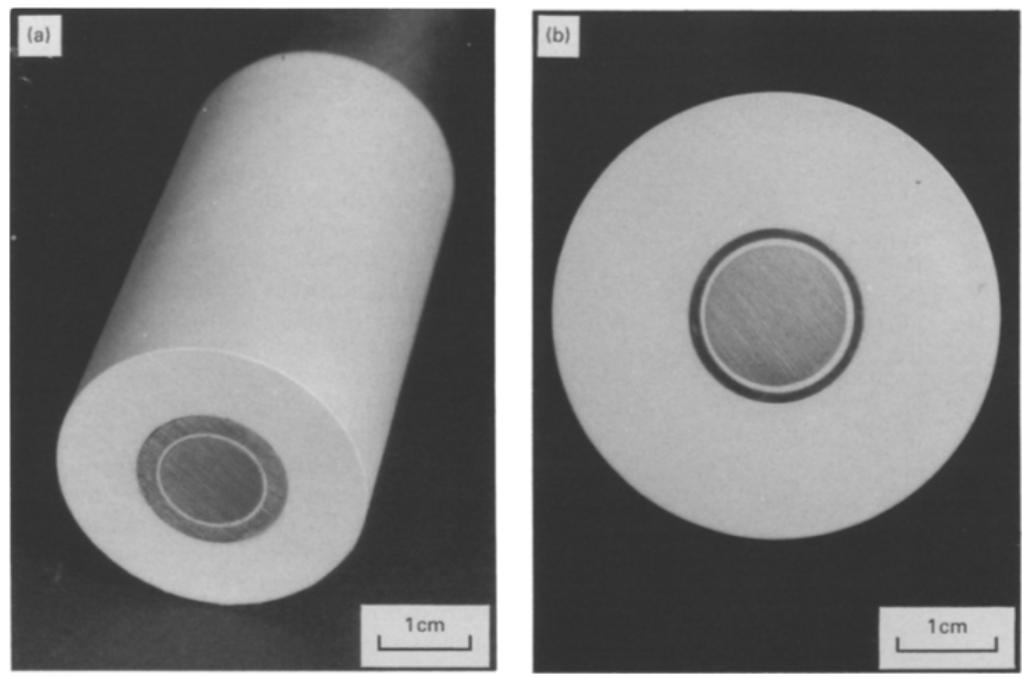

Figure 2. A photograph of typical high temperature Au-Mo RRDE (Stojanovic et al., 1995)

Sunarso, Torriero, Zhou, Howlett \& Forsyth (2012) prepared perovskite oxide electrocatalysts $\left(\mathrm{LaMO}_{3}\right.$ and $\left.\mathrm{LaNi}_{0.5} \mathrm{M}_{0.5} \mathrm{O}_{3}\right)(\mathrm{M}=\mathrm{Ni}, \mathrm{Co}, \mathrm{Fe}, \mathrm{Mn}$ and $\mathrm{Cr})$ by a combined ethylenediaminetetraacetic acid-citrate complexation technique and subsequent calcinations at $1000^{\circ} \mathrm{C}$ in air. The effect of these electrocatalyst properties on the oxygen reduction reaction (ORR) was studied in alkaline potassium hydroxide solution using the rotating ring-disk and electrode rotating disk systems. Voltammograms for the reduction of oxygen and simultaneous oxidation of $\mathrm{HO}_{2}{ }^{-}$were performed using a four-electrode arrangement in a glass cell with $100 \mathrm{ml}$ employing the rotating ring disk electrode apparatus (RRDE-3A). This comprises a platinum wire counter electrode, a Pt ring electrode $\left(0.189 \mathrm{~cm}^{2}\right.$ area $)$, an $\mathrm{Ag} \mid \mathrm{AgCl}(3 \mathrm{M} \mathrm{NaCl})$ reference electrode, and a glassy carbon disk electrode $\left(0.126 \mathrm{~cm}^{2}\right.$ area). The rotating disk electrode runs were performed utilizing a conventional three-electrode arrangement including a Pt disk electrode with $3 \mathrm{~mm}$ diameter $\left(0.071 \mathrm{~cm}^{2}\right.$ area $)$ and similar counter and reference electrodes were used in the RRDE experiments.

Popov (1993) utilized galvanostatic pulse, pulse reverse and linear sweep voltammetry methods to study the plating of nickel-iron alloys in the presence of organic additives. They also investigated the effects of reverse current densities, the presence of organic additives in the bath, pulse current densities and electrode rotation speed on galvanostatic pulse and pulse reverse Fe-Ni plating using rotating disk electrodes in sulfate baths. Their study of the dissolution and electrodeposition of alloy and single metal was performed using a linear sweep voltammetry (LSV) approach, which was applied to dissolve anodically the alloy by a fixed and rotating disk electrode. The working electrodes were Pt rotating disk electrodes. Determining the optimum concentration of saccharin to use in the electrodeposition process was the main objective of this study.

Jorge, Neto \& Rocha (2007) evaluated and suggested a bismuth film electrode as an environmentally friendly sensor for the determination of trace levels of thallium (I) in non-deoxygenated solutions. By anodic stripping voltammetry at a rotating disk bismuth film electrode, the determination of thallium was done using acetate buffer as the supporting electrolyte. Based on the use of the rotating disk electrode, the potentialities to operate in flow systems were reinforced by the success of its performance under hydrodynamic conditions. The good performance of the rotating disk bismuth film electrode and low toxicity of bismuth make the voltammetric measurements an attractive and promising sensor to monitor toxic chemical species in environmental matrices using a clean methodology.

Jesusa et al. (2012) demonstrated the possibility of electrodeposition of Pt nanoparticles onto unsupported SWCNTs and reported the use of the rotating disk slurry electrode (RODSE) approach for the bulk preparation of Pt/SWCNTs, which were characterized electrochemically using the cyclic voltammetry method (CV) and characterized physically by X-ray diffraction (XRD), transmission electron microscopy (TEM), and energy dispersive spectroscopy- X-ray fluorescence (EDS-XRF). The prepared Pt/SWCNTs were employed as the sensing material for detection of the $\mathrm{CH}_{4} \mathrm{ppm}$ level at room temperature. This work introduces a novel and alternative way to prepare metallic nanoparticles supported on SWCNTs on a large scale. In the same way, (Rodríguez-Calero, Rivera, Tryk, Scibioh \& Cabrera, 2010) described the large-scale production of well dispersed Pt nanoparticles on unsupported carbon black using the rotating disk-slurry electrode (RODSE) 
system.

Panella, Ydstie \& Prieve (2011) proposed a technique for the rapid deposition of titania nanoparticles onto transparent conductive oxide surfaces for use in dye solar cell anodes. The surface potential of submerged oxide surfaces such as tin oxide and titania can be controlled by manipulating the $\mathrm{pH}$ and ionic strength of an aqueous solution. Fluid flow, such as that of an impinging jet or rotating disk, was employed to deliver nanoparticles adequately close to the surface. The rotating disk electrode apparatus, shown in Figure 3, was used to monitor the particle deposition by measuring the zeta potential of a surface. The zeta potential of a clean disk was calculated as a function of solution $\mathrm{pH}$ between 3.5 and 10 , which was adjusted by using a background salt of 0.5 $\mathrm{mm}$ sodium nitrate with nitric acid and sodium hydroxide. The volume of the bath used for the rotating disk experiments was about $450 \mathrm{ml}$.

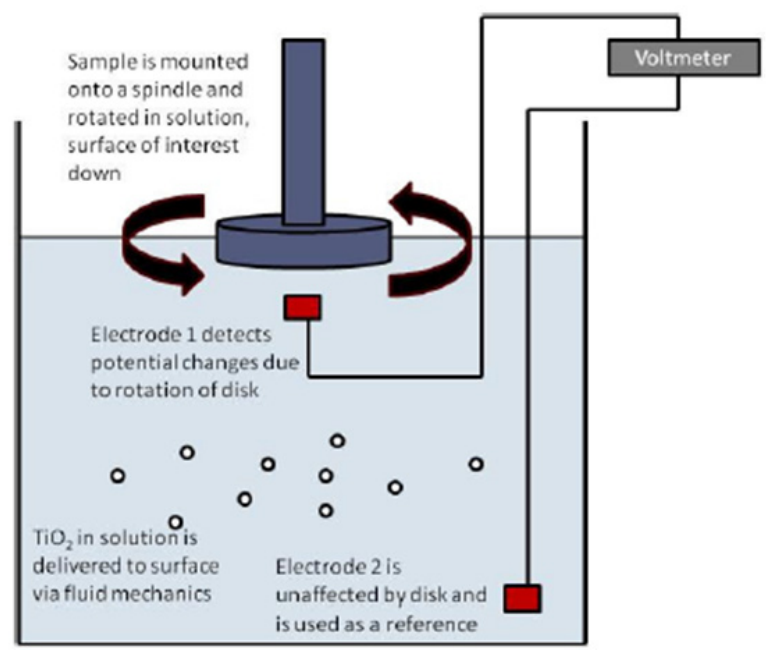

Figure 3. Apparatus for measuring zeta potential using a rotating disk (Panella et al., 2011)

Ying (1988) developed a mathematical model to simulate the electrodeposition of $\mathrm{Cu}-\mathrm{Ni}$ alloy from citrate solutions onto a rotating disk electrode under potentiostatic control. The effects of forced convection, ionic migration, homogeneous equilibria, and diffusion were involved in this model. Hydrogen evolution, copper deposition, and nickel deposition were the three major electrochemical reactions addressed in the present model. In their previous work, the authors determined experimentally the influence of forced convection, ionic migration, homogeneous equilibria, and diffusion on the $\mathrm{Cu}-\mathrm{Ni}$ alloy deposition process in citrate solutions using a rotating disk electrode. The experiments were performed at a constant rotation speed (1600 rpm) and room temperature.

Viel, Bureau, Deniau, Zalczer \& Lecayon (1999) performed the electropolymerization of methacrylonitrile under voltammetric conditions using a platinum rotating disk electrode (RDE) spinning at a high angular rotation rate $(\omega=10000 \mathrm{rpm})$ in anhydrous acetonitrile. Then they analyzed the rotating disk electrode surface by X-ray photoelectron spectroscopy (XPS) and ellipsometry at the end of the experiment. In the same procedure, (Tanguy, Deniau, Zalczer \& Lécayon, 1996) suggested that the use of a rotating disk electrode (RDE) spinning at a very high rotation rate could provide interesting information towards deciding which mechanism is the most feasible. Rotating disk electrode voltammetry has been shown to be a fast, inexpensive, and simple technique for studying substrate kinetics at mutant catecholamine and wild-type transporters. It has become an effective instrument in the field of neuropharmacology and neurochemistry for the analysis of the transport kinetics of dopamine (DA) and cocaine's mechanism of inhibition of DA transport in tissue homogenates (McElvain \& Schenk, 1992; S. M Meiergerd, Hooks \& Schenk, 1994; S. M Meiergerd \& Schenk, 1994; Susan M Meiergerd, Mcelvaint \& H, 1994; Povlock \& Schenk, 1997).

Burgess, Kable \& Justice (1999) examined the transport of the substrates dopamine (DA) at the human norepinephrine transporter (HNET) expressed stably in LLC cells. In addition, they described a double electrode configuration (rotating and stationary working electrodes) for the electrochemical cell. Rotating disk voltammetric measurements were made using a $3 \mathrm{~mm}$ diameter glassy carbon working electrode driven by an AFMSRX Analytical Rotator System. McBreen et al. (1984) described a rotating disk electrode apparatus for 
studying fuel cell reactions at high temperatures and pressures, and provided primary data for oxygen reduction in $89.5 \% \mathrm{H}_{3} \mathrm{PO}_{4}$ at temperatures and pressures up to $205{ }^{\circ} \mathrm{C}$ and $7.6 \mathrm{~atm}$, respectively. In the work by (Uribe-Godínez, Castellanos, Borja-Arco, Altamirano-Gutiérrez \& Jiménez-Sandoval, 2008), oxygen reduction and hydrogen oxidation in $0.5 \mathrm{M} \mathrm{H}_{2} \mathrm{SO}_{4}$ were performed using novel osmium electrocatalysts. These electrocatalysts were characterized electrochemically using rotating disk electrode measurements at room temperature, with cyclic and linear sweep voltammetry, and structurally characterized by scanning electron microscopy, X-ray diffraction, and FT-IR spectroscopy. The rotating disk electrode studies were implemented in a conventional electrochemical cell, which comprised three compartments for the work, a water jacket, counter electrode and reference electrode. The voltammetry studies were carried out by a Radiometer Analytical BM-EDI101 glassy carbon rotating disk electrode with a CTV101 speed control unit.

\subsection{Rotating Disk Reactor}

One of the common types of rotating disk reactor is a rotating disk acid reaction system (CRS-100) which has utilized the common oil industry acids (acetic acid, hydrochloric, hydrofluoric, etc.) to calculate rock/acid reaction rates at temperatures up to $250{ }^{\circ} \mathrm{C}$ and pressures of 3000 psig standard and 5000 psig and $7240 \mathrm{psig}$ as options. The reaction rates of carbonate and dolomite samples can be estimated from the experimental and sample collection data from the CRS-100 and the chemical analysis of the reactant. These reaction rates can be employed in the design of effective acid stimulation treatments of wells. The apparatus consists of a standard 500 $\mathrm{ml}$ capacity acid cell (500 $\mathrm{ml}$ and $1000 \mathrm{ml}$ options) to hold a core sample disk, which is rotated by the magnetic drive mechanism. The sample is immersed to an exact and known depth in the measurement cell, which is provided by the acid from the pre-charge cell by gas drive. Both acid cells are either cooled or heated to the desired temperature before displacement, and pressurized to the required pressure when displaced into the primary cell, as shown in Figure 4. The operating software controls most of the reaction parameters such as test duration, acid displacement, rotation speed, temperature, and pressure. The software permits the collection of a number of reactant samples at preselected time intervals. Between 100 and $2000 \mathrm{rpm}$ is the rotating speed range of this rotating reactor.

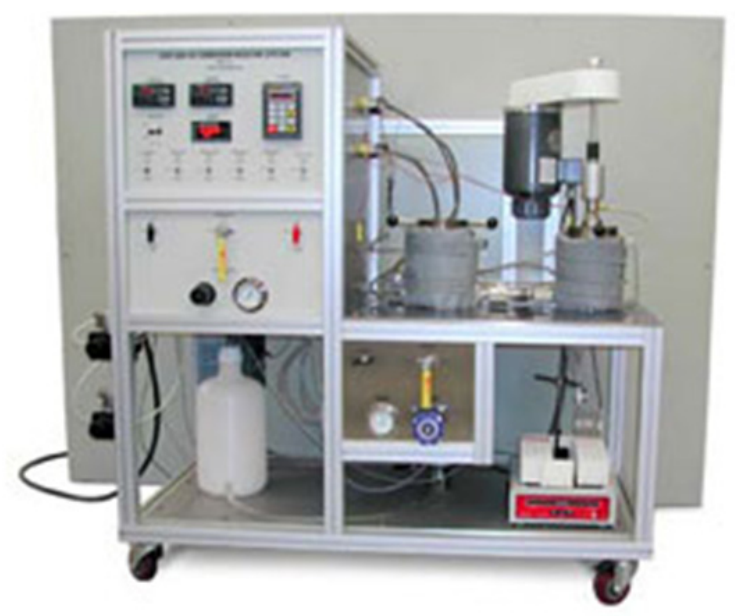

Figure 4. The rotating disk acid reaction system (CRS-100)

D. B. Boomer \& McCune (1972) designed and used a rotating disk apparatus for studying the reaction between calcium carbonate disks and hydrochloric acid. This apparatus can be operated in enormously corrosive liquid environments under controlled pressures and temperatures up to $70 \mathrm{~atm}$ and $150{ }^{\circ} \mathrm{C}$. The calcium carbonate disks were cut from a white Vermont marble (analyzed as $98-99 \%$ calcium carbonate) with $5.1 \mathrm{~cm}$ in diameter and $0.64 \mathrm{~cm}$ thickness. The equipment is assembled in an insulated box using an air bath for temperature control.

Igimi \& Carey (1981) studied the dissolution kinetics of the common crystalline forms of cholesterol (anhydrate and monohydrate) in ursodeoxycholate and chenodeoxycholate solutions by powder dissolution, static disk, and rotating disk approaches. The rotating disk configuration was used to examine the interfacial kinetics and relative contributions of diffusion to control the dissolution of cholesterol. As in the static disk apparatus, thin cholesterol disks $(0.75-1.5 \mathrm{~mm})$ were prepared in a stainless steel die of $30.0 \mathrm{~mm}$ (id.) under a pressure of 
10,000 psi. The inverted die plus cholesterol disk was then screwed onto the tip of a straight stainless steel impeller rod, the free end of which exited through Teflon collars in the central opening of the glass cap to become the drive shaft of a synchronous motor (Figure 5).

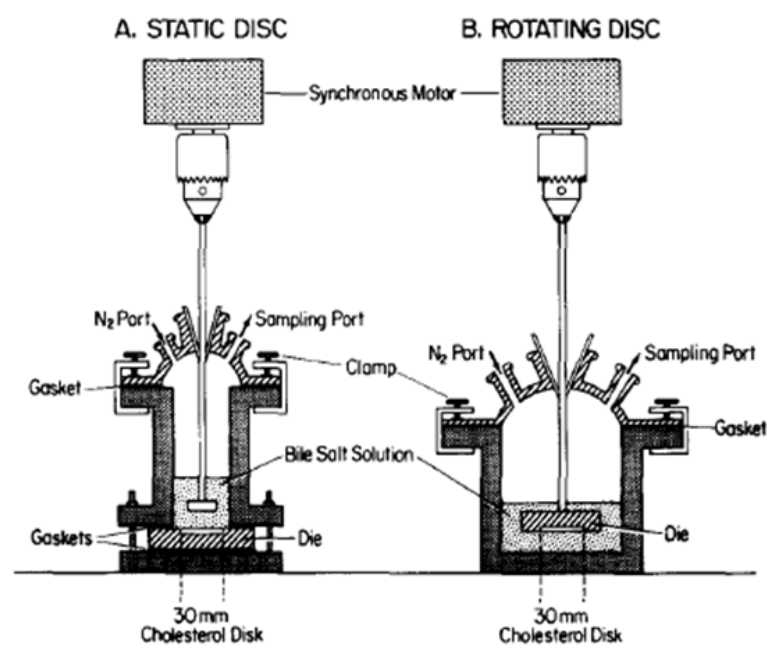

Figure 5. Diagrammatic representation of A) static disk and B) rotating disk apparatus for dissolution rate and equilibrium solubility studies (Igimi \& Carey, 1981)

Shima, Tomaru, Ihara \& Miura (1992) investigated the effects of peripheral temperature, velocity, and static pressure on the cavitation behaviour of stainless steel and the erosion rate over a wide range using a newly constructed rotating disk apparatus. The experiments were performed at a high peripheral speed range of 65.4$77.6 \mathrm{~m} / \mathrm{s}$, where nobody has reported on the erosion process with a rotating device. The test specimens were utilized with a through-hole to induce cavitation and a range to be eroded in a body. The rotating disk was connected to a horizontal spindle supported by conventional oil lubricated antifriction bearings (Figure 6). Steller et al. (1974) summarized that the modelling of cavitation erosion using a rotating disk apparatus is closer to the process with natural field conditions than with a magnetostrictive approach. Many researchers examined the influences of velocity (Iwai \& Okada, 1987; P.V. Rao \& Rao, 1981), air content (Hansen \& Rasmussen, 1968), time (Lichtman \& Weingram, 1964; Lightman, Kallas, Chatten \& Cochran, 1961; P. V. Rao, P. C. S Rao \& N. S. L. Rao, 1980; Wood, Kundsen \& Hammitt, 1967), and scale (P. V. Rao \& Buckley, 1987) on the erosion rate of different materials using rotating disk systems. Despite the numerous devices developed, the rotating disk apparatus seems to be the best to simulate the erosion in rotary machinery such as hydraulic turbines and pumps.

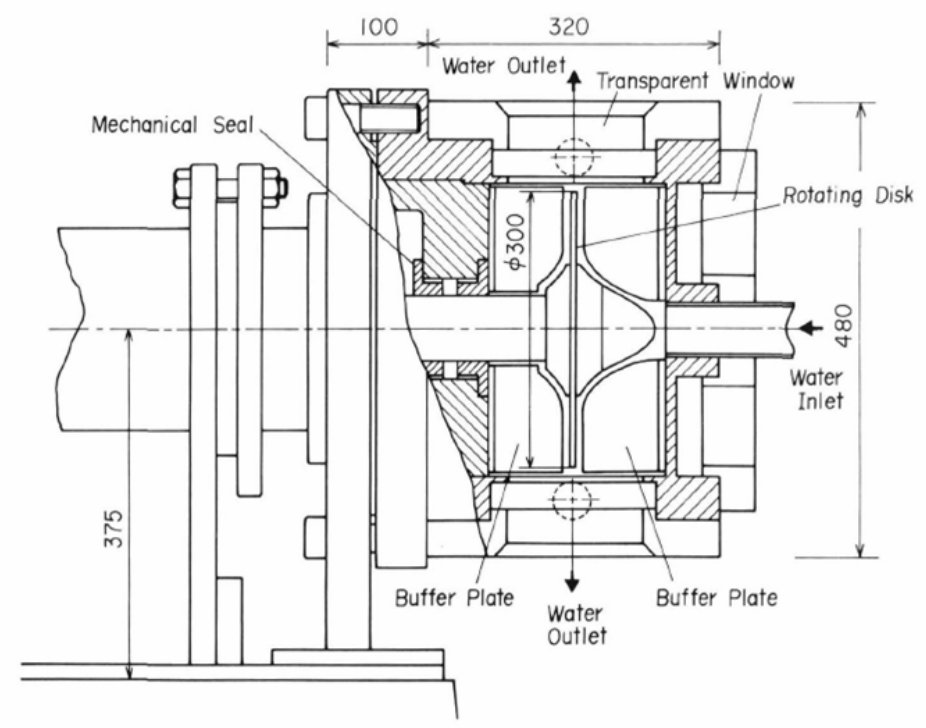

Figure 6. Schematic of working chamber (Shima et al., 1992) 
Krueger, Patnaik, Wang \& Flytzani-Stephanopoulos (1996) presented a detailed model for predicting spatial uniformity and etch rates for $\mathrm{CH}_{3} \mathrm{I}$ vapour etching in a vertical rotating-disk organometallic vapour phase epitaxy (OMVPE) reactor (Figure 7). The modelling data was compared with experiments performed in the vertical reactor at numerous temperatures $\left(525-590^{\circ} \mathrm{C}\right)$ and $\mathrm{CH}_{3} \mathrm{I}$ mole fractions $(0.005-0.05)$ in an $\mathrm{H}_{2}$ carrier gas. The present model was a modification of a previous one for the same reactor (Patnaik, Brown \& Wang, 1989), and has been extended to involve radiative heat transfer and $\mathrm{CH}_{3} \mathrm{I} / \mathrm{H}_{2}$ gas phase reaction chemistry. The main advantage of this reactor is that a high degree of radial uniformity deposition can be achieved through adjustment of the disk rotation rate.

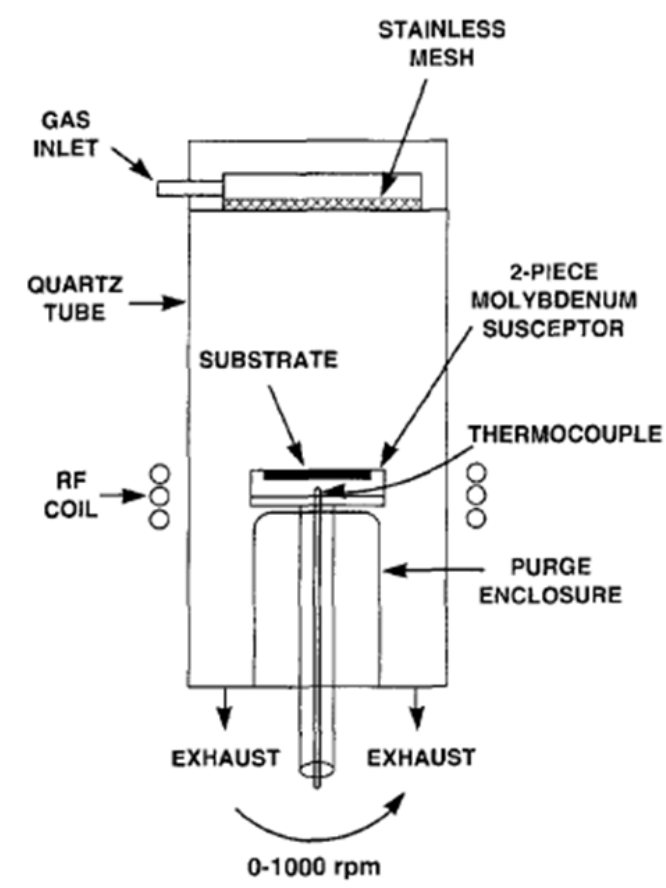

Figure 7. Schematic of vertical rotating disk reactor (Krueger et al., 1996)

Antileo, Roeckel \& Wiesmann (2003) experimentally studied the production of high nitrite by nitritation using a continuous single rotating disk reactor (RDR) and then compared this to a modelled continuous completely stirred tank reactor (CSTR). Incomplete nitrification with high nitrite accumulation has three practical advantages: lower sludge production during denitrification, lower oxygen consumption, and less need for organics for denitrification. Immobilized nitrifying bacteria were employed to improve the nitrification process because it enables higher solids retention times and nitrogen load operation, compared with suspended systems.

The main aim of the spinning disk reactor concept was to accelerate the process operation based on the surface rotation technique, which presents heat and mass transfer limitations. Liquid phase reactions between aqueous crystal violet and sodium hydroxide solution were described in the present work using a spinning disk reactor, and the reactor's hydraulic performance was evaluated using classical tracer-response methods. The influences of rotational speed and flow rate on mixing were investigated. The present reactor (Figure 8) involved a flat stainless steel circular disk with a diameter of $150 \mathrm{~mm}$ and $2 \mathrm{~mm}$ thickness, coupled coaxially with a rotating hollow shaft motorized by a belt drive. This shaft was used to supply one of the reactant liquids, while the second liquid was sprayed on to the top surface of the disk by a nozzle, located $30 \mathrm{~mm}$ from the top surface of the disk, in a cylindrical vessel $200 \mathrm{~mm}$ in diameter, provided with a single vent and outlet port (Robertson \& Weatherley, 2004). 


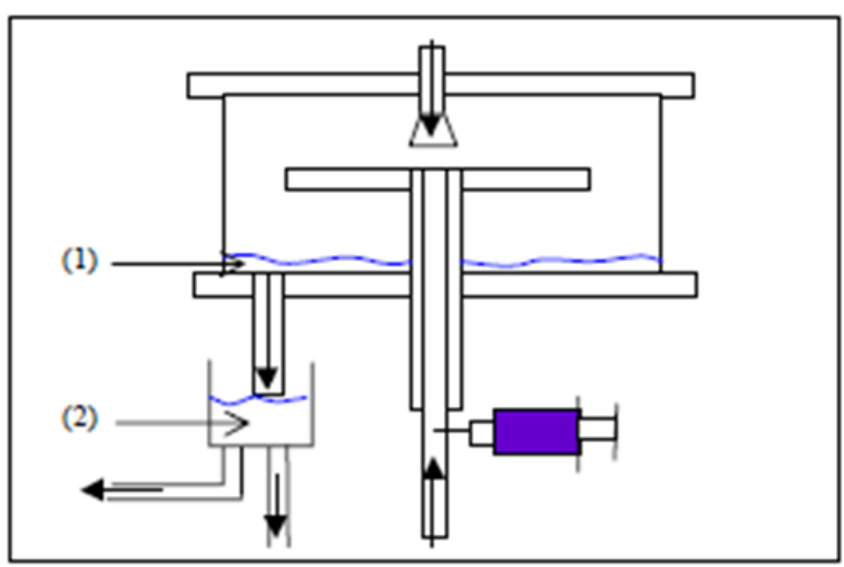

Figure 8. Spinning disk reactor arrangement (Robertson \& Weatherley, 2004)

Bazanini, Bressan \& Klemz (2008) studied the failure by cavitation in metallic specimens using a compacted rotating disk device which involves cavitation inducers with a disk and specimens fixed on it rotating in water to generate cavitating flow. After 25 hours working in cavitating conditions, cast, brass, iron and aluminium were worn by the cavitation phenomenon, resulting in mass loss and pitting formation. Details of the test device and test specimens are illustrated in Figure 9. The peripheral was kept constant at $4400 \mathrm{rpm}$ in the present work because it is affected by the specimen's position on the disk.

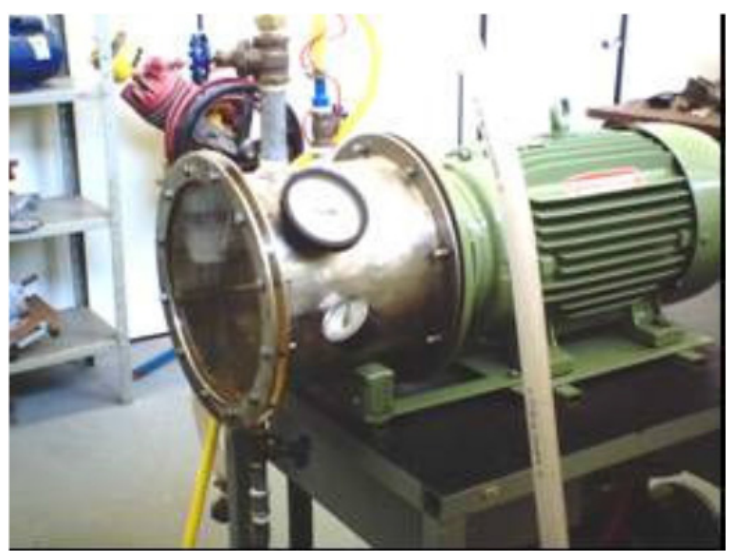

(a)

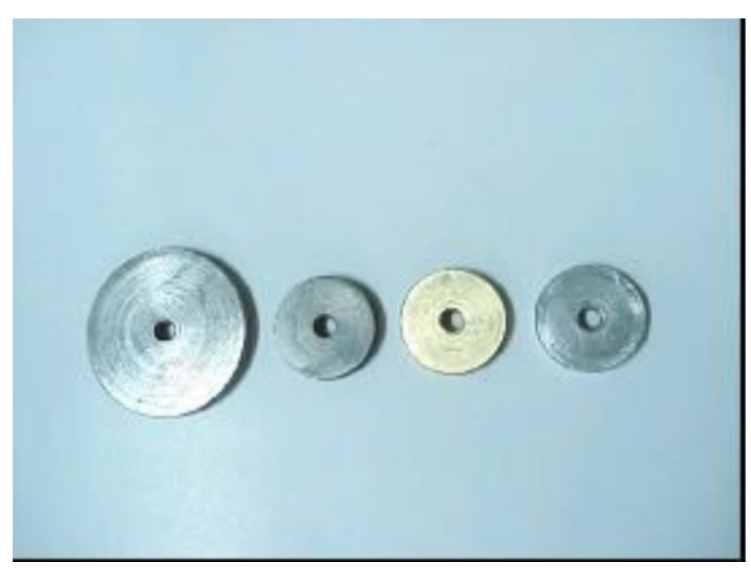

(b)

Figure 9. a) The test device, b) The test specimens (Bazanini et al., 2008)

M. Stoller, Miranda \& Chianese (2009) studied the feasibility of producing hydroxyapatite (HAP) nanoparticles in a continuous mode using a rotating disk reactor, and investigated the influence of the feed location of the reagents over the rotating disk surface. A great effect of the feed location on the particle size distribution of the produced HAP was noticed, and particles smaller than $100 \mathrm{~nm}$ were produced only with the best feed location of the reagents. The hydroxyapatite nanoparticles were produced by the reaction between two aqueous solutions of ammonia orthophosphate and calcium chloride at $50{ }^{\circ} \mathrm{C}$, then precipitation of the produced HAP. The adopted apparatus is provided with a disk of $50 \mathrm{~mm}$ diameter rotating at $1500 \mathrm{rpm}$. The two reactant solutions were separately supplied at the same distance from the center of the disk (see Figure 10). 


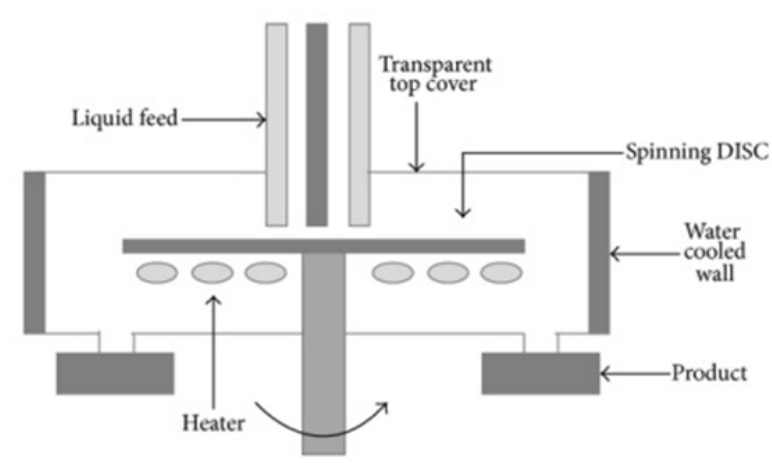

Figure 10. Scheme of the adopted rotating disk reactor (M. Stoller, Miranda \& Chianese, 2009)

Korzhova (2009) developed a new technique for the tracking and analysis of fluid flow. The moving waves and computed controlling film flow parameters were revealed by this technique developed for the fluid flowing over a rotating disk. A liquid film flow over a horizontal rotating disk has numerous industrial applications such as bioengineering, chemical engineering, and pharmaceuticals. One of the common applications at the present time is the transfer of gases (e.g., carbon dioxide) into liquids. Figure 11 shows a liquid film flowing over a rotating disk with $500 \mathrm{rpm}$ angular velocity and $0.8 \mathrm{l} / \mathrm{m}$ flow rate (Q).

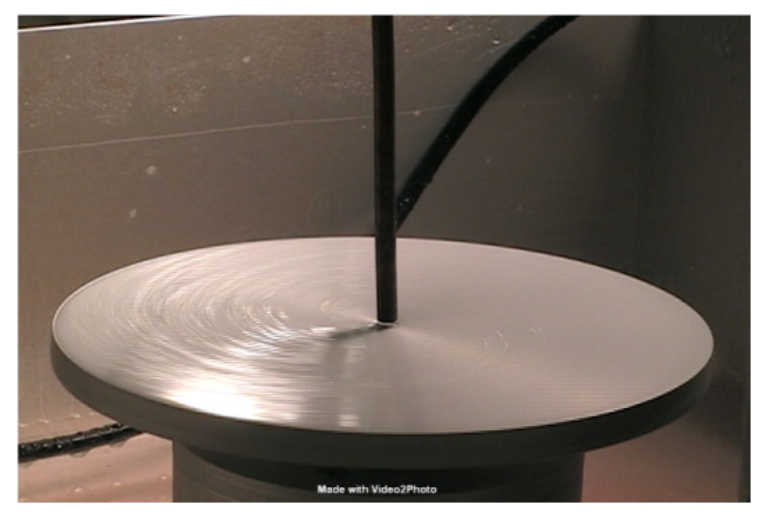

Figure 11. Rotating disk close-up (Korzhova, 2009)

For many years the characterization of solid drugs has been performed using rotating disk intrinsic dissolution rate (IDR) apparatus, involving studies of dissolution-pH rate profiles in the presence of binding agents, various excipients/delivery vehicles, and buffers (Amidon, Lee \& Topp, 2000; Jinno, Oh, Crison \& Amidon., 2000; Li, Doyle, Metz, Royce \& Serajuddin, 2005; Li, M. Wong, et al., 2005; McNamara \& Amidon, 1986, 1988; Mooney, Mintun, Himmelstein \& Stella, 1981a, 1981b; Serajuddin \& Jarowski, 1984, 1985; Sheng, Kasim, Chandrasekharan \& L., 2006; Southard, Green, Stella \& Himmelstein, 1992; Yu, Carlin, Amidon \& Hussain, 2004).

Avdeef \& Tsinman (2008) investigated the possibility of using a miniaturized disk intrinsic dissolution rate (IDR) apparatus to evaluate the Biopharmaceutics Classification System (BCS) solubility class, and to improve a technique which can be used to compare IDR measurements performed in media of various buffer capacities. The disk IDR values of 14 model drugs were determined at $37^{\circ} \mathrm{C}$ in US Pharmacopeia buffers at $\mathrm{pH} 1.2,4.5$, and 6.8 .

Schwartz, Stephenson, Hernandez, Jambang \& Boles (2010) presented the growth of Staphylococcus aureus using the rotating disk biofilm reactor and the drip flow biofilm reactor. The rotating disk reactor comprises a Teflon disk containing recesses for removable coupons (Pitts et al., 2001), as shown in Figure 12. These coupons can be prepared from any machinable material. The entire disk containing 18 coupons was located in a $1000 \mathrm{ml}$ glass side-arm reactor vessel. The disk was rotated by a magnetic stirrer while a liquid growth medium was circulated through the vessel. The coupons were removed from the reactor vessel and then scraped to collect the 
biofilm sample for further study or microscopy imaging. Rotating disk reactors have been designed for laboratory calculations of the performance of anti-fouling materials, biocide efficacy, and biofilm removal (Boles, Thoendel \& Singh, 2004, 2005; Hentzer et al., 2001; Lin, Chen \& Huang, 2004).
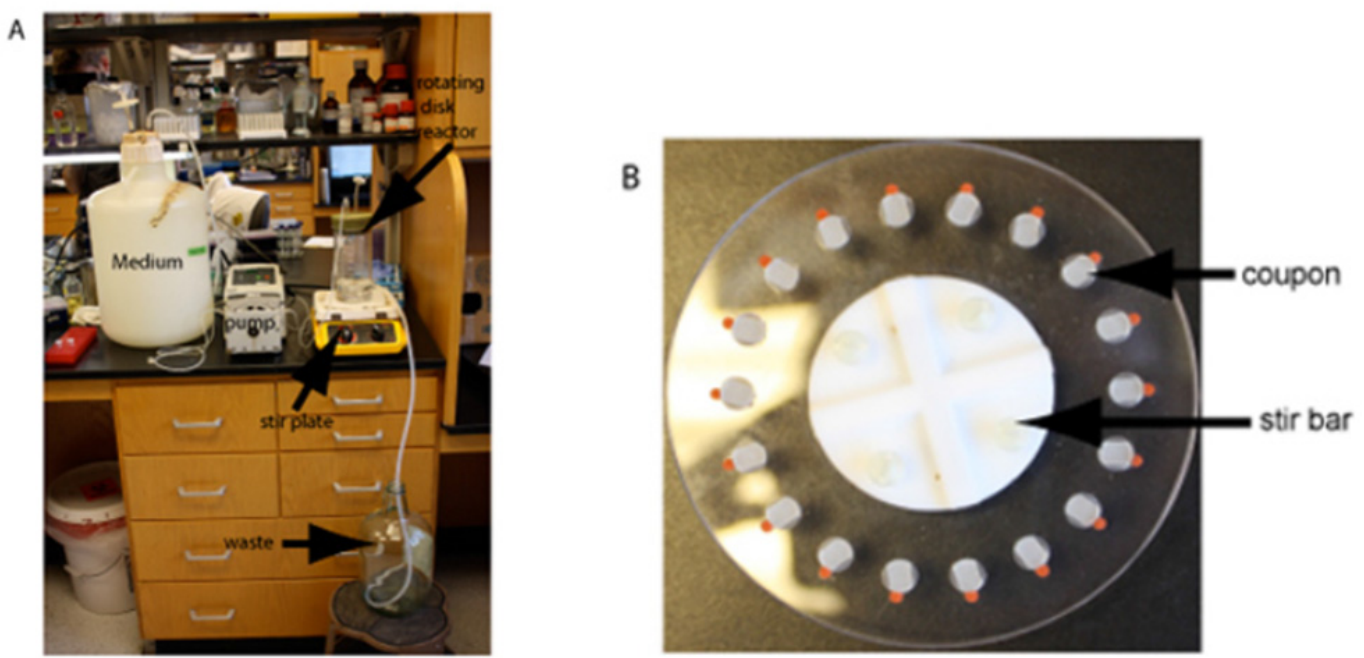

Figure 12. The rotating disk biofilm reactor. A) Example of a running spinning disk reactor. B) Close-up view of a spinning disk (Schwartz et al., 2010)

Neopane, Sujakhu, Shrestha, Subedi \& Basnet (2012) briefly discussed the laboratory studies of the particle size effect on erosion prediction in a rotating disk apparatus (RDA) which can address cavitation and erosion of material due to sand-laden water flow at high speed. The main purpose of this type of test rig is to achieve a high relative velocity of the test specimen with respect to the water. They noticed that the intensity of erosion (weight loss) was affected by the sediment size and run time, respectively, when all other variables were kept constant.

The intrinsic dissolution rate (IDR) measurement in the early drug discovery process was evaluated using a miniaturized stationary disk system (MSDS) and a miniaturized rotating disk system (MRDS) (Tseng, Patel, \& Zhao, 2014). Chloramphenicol was used to evaluate these two apparatuses as a model drug with sample sizes of 3-10 mg. The influence of dissolution volume, compression force, drug loading, and disk distance on the IDR was investigated on the two miniaturized apparatuses. It was noticed that the disk distance and dissolution volume have significant effects on the dissolution rate by MSDS. This study indicated that both miniaturized systems proved to be reliable for IDR measurements with a small quantity of material and more effective than other methods (e.g., Wood's rotating disk system (WRDS), and solubility measurement) in the early drug discovery phase. Figure 13 shows examples of WRDS, MRDS and MSDS apparatus.

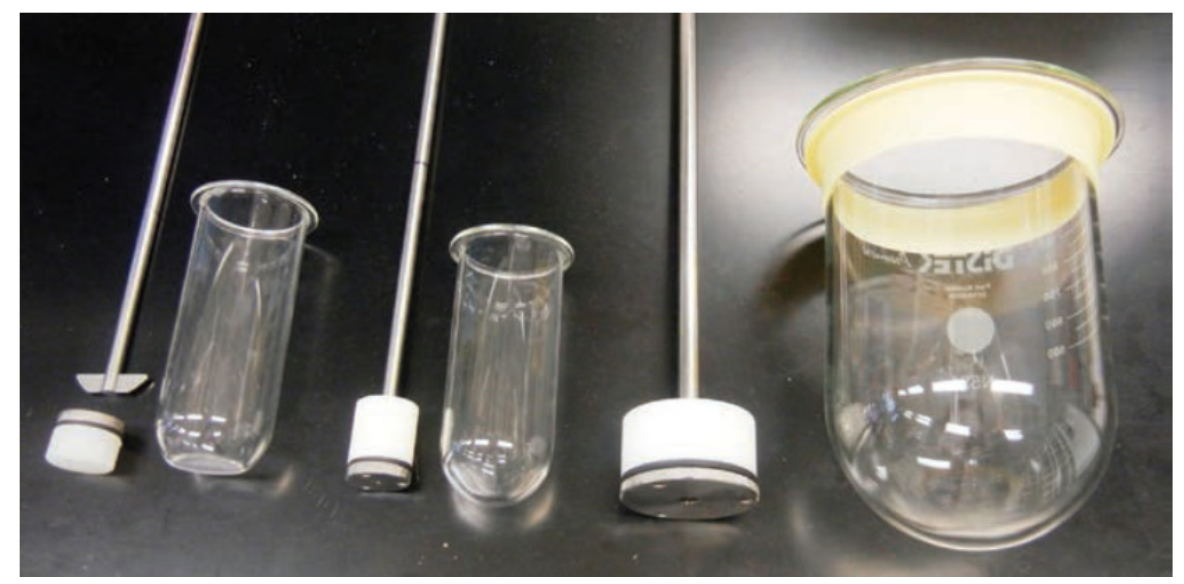

Figure 13. Miniaturized stationary disk system, miniaturized rotating disk system, and Wood's rotating disk system (left to right) (Tseng et al., 2014) 
Recently, the production of nanoparticles using a rotating disk reactor (RDR) has been proposed for the production of several compounds (Burns \& Jachuck, 2005; Cafiero, Baffi, Chianese \& Jachuck, 2002; Stoller, Miranda \& Chianese, 2009). This kind of apparatus mostly comprises a horizontal rotating disk confined in a cylindrical case, as shown in Figure 14. The reactants are provided to the central part of the disk surface and start to move at a high radial velocity due to the centrifugal force effect. Consequently, a very thin film is formed and the residence time on the disk is very short. From the disk border, the liquid is moved to the case wall and down to the collecting basin, where the continuous product is removed from the downcomer. Rotating disk reactors have many benefits compared with other mixing devices in the precipitation process:

1) In the liquid film flowing over the disk surface, a micro-mixing condition can be achieved with reasonable energy consumption (Burns \& Jachuck, 2005; Cafiero et al., 2002).

2) The growth rate after nucleation is limited by the small liquid residence time which allows the production of nanoparticles.

3) Continuous operation can be conducted.

4) This apparatus may be used to allow precipitation from the gas-liquid reaction (Burns \& Jachuck, 2005).

The operating conditions strongly affect the rotating disk reactor performance. For example, the attainment of micro-mixing is determined by the influence of the rotation speed (Cafiero et al., 2002), and the size of the particles produced is strongly affected by the feeding point location, as recently shown by (Stoller et al., 2009). Thus, the film hydrodynamics characterizations are very important to optimize the operating conditions of the RDR. Hydrodynamics over an RDR, including the liquid turbulence, are predicted by (Caprariis, Stoller, Chianese \& Verdone, 2015) using a CFD approach. Some preliminary results are reported and compared with the experimental results obtained by (Burns, Ramshaw \& Jachuck, 2003).

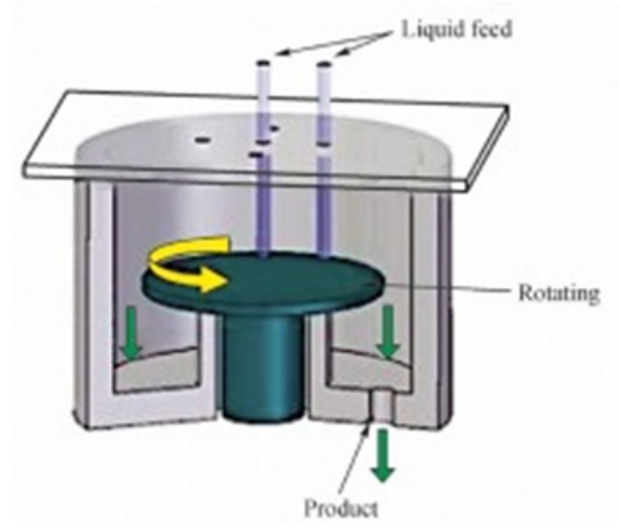

Figure 14. Scheme of the rotating disk reactor (Caprariis et al., 2015)

\subsection{Drag Reduction Using Rotating Disk Apparatus (RDA)}

The rotating disk apparatus (RDA) used in drag reduction applications is an equipment for simulating the external flow and is used for turbulent drag reduction characterization, namely, for measuring the torque among a Newtonian fluid and dilute suspension which contain a drag reduction agent. The percentage of drag reduction is measured by the following equation:

$$
\% \mathrm{DR}=(\mathrm{Ts}-\mathrm{Tp}) / \mathrm{Ts} \times 100
$$

Where $T_{S}$ is the measured torque of the solvent alone, and $T_{P}$ is the measured torque of the polymeric solution. In addition, the Reynolds number definition is:

$$
\mathrm{NR}_{\mathrm{e}}=\rho \omega \mathrm{r}^{2} / \mu
$$

Where $\rho$ is fluid density, $\omega$ is angular velocity [ $2 \pi$ (revolutions per minute) $/ 60 \mathrm{rad} / \mathrm{s}$ ], $\mathrm{r}$ is radius of disk and $\mu$ is fluid viscosity [Pa.s]. The maximum drag reduction that can be achieved in a pipe flow is $80 \%$, while the maximum drag reduction of rotating disk flow is only $40 \%$, because of the difference in the total drags and the friction between the inner flow (pipe flow) and external flow (rotating disk flow) (H. J. Choi \& Jhon, 1996). The rotating disk apparatus was adopted in this study because the phenomenon of DR has not been studied in external flows as extensively as in pipe flows (H. J. Choi, Kim \& Jhon, 1999; H. J. Choi \& Jhon, 1996; C. A. Kim et al., 1999; S. T. Lim et al., 2002; Mccormick, Heater, Morgan \& Safieddine, 1990; McCormick, Hester, 
Morgan \& Safieddine, 1990; Rodriguez \& Winding, 1959). This apparatus was used to describe the external flow, including the flow over flat plates, as well as the flow around submerged objects (Tong et al., 1990). Most previous work on drag reduction in a rotating disk apparatus has used the same design of RDA with different disk and fluid container dimensions. The main parts of this apparatus are: (1) Speed controller, (2) Thermocouple, (3) Motor, (4) Solution container, (5) Water bath, (6) Water-circulating system, (7) Thermometer, and (8) PC, as shown in Figure 16 (J. T. Kim, C.A. Kim, Zhang, Jang, \& Choi, 2011).

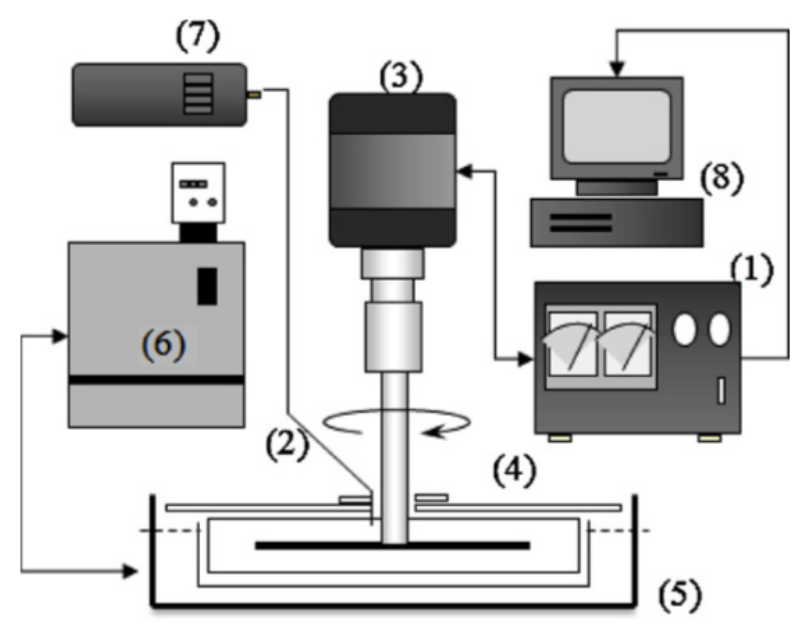

Figure 15. Experimental set-up of a rotating disk apparatus for drag reduction measurement (J. T. Kim et al., 2011)

C. A. Kim et al. (2000) measured drag reduction for different concentrations of xanthan gum and PEO solution and mentioned that the decrease in the $\% \mathrm{DR}$ for lower polymer concentrations was stronger at a specific rotating speed (Figure 16). Also, in comparison, a higher initial \%DR was perceived for the PEO solution. In addition, they measured the \%DR for PEO at five different temperatures (Figure 17) which showed that the \%DR of the PEO solution declines with temperature. The time-dependence of the $\% \mathrm{DR}$ explains the degradation of polymer, which is stronger for lesser polymer concentrations.

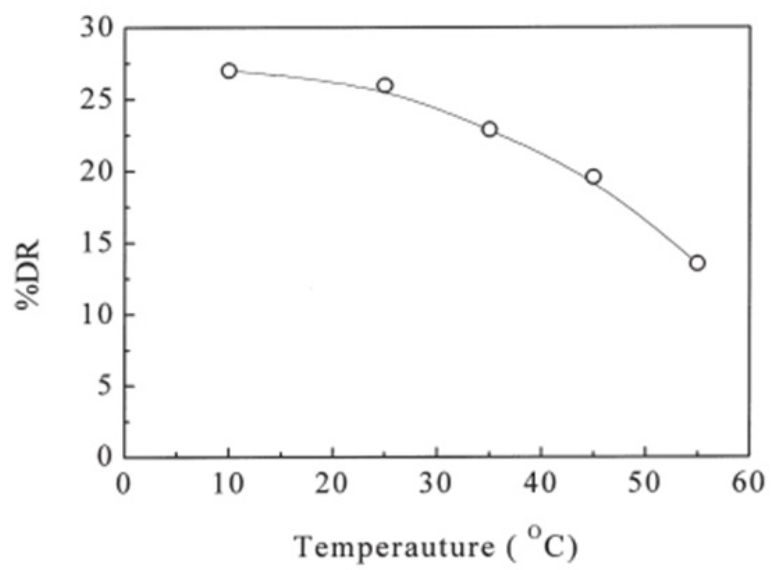

Figure 16. \%DR of PEO vs. polymer concentration at $2040 \mathrm{rpm}$ and $25{ }^{\circ} \mathrm{C}$ (C.A. Kim et al., 2000) 


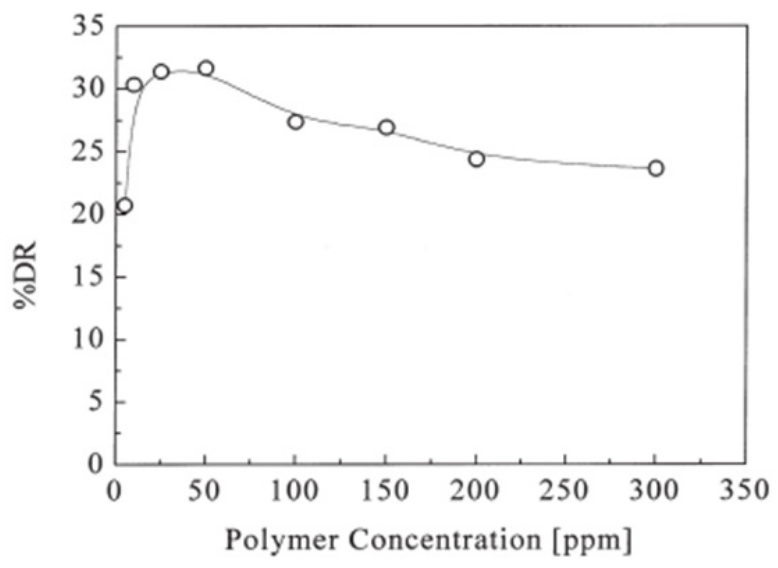

Figure 17. Temperature effect of \%DR for a 50 ppm PEO (C.A. Kim et al., 2000)

To investigate the influence of solvent on drag reduction characteristics, two different solvents (cyclohexane and xylene) were used with different concentrations of oil soluble polyisobutylene (PIB) using rotating drag reduction (RDA) (H. J. Choi et al., 1999) and the results were compared with previous work on a system of PIBkerosene (C. A. Kim et al., 1997). They also obtained a linear correlation between polymer concentration $(C)$ and C/DR for different molecular weights of PIB. The RDA used was the same as previously reported (H. J. Choi \& Jhon, 1996). All experiments were performed using a constant angular velocity at $1800 \mathrm{rpm}$, with a Reynolds number of $9.9 * 10^{5}$. It was found that the intrinsic concentration was an extremely useful quantity in normalizing the DR data for a homologous series of PIB, and the characteristic value $(K)$ depended on the solvent system. A polysaccharide xanthan gum polymer in an aqueous solution was evaluated as a drag reducing agent using a rotating disk apparatus (RDA) (Sohn et al., 2001). The effects of various factors such as rotational disk speed, temperature, solution ionic strength, polymer concentration, and polymer molecular weight on the drag reduction efficiency were also investigated. Different fractions of molecular weights of xanthan gum were obtained by the ultrasonic degradation method. All measurements were implemented with the same RDA used by (C. A. Kim et al., 1997; C. A. Kim et al., 1998), with a fixed rotation speed of $1800 \mathrm{rpm}$ and temperature of $25{ }^{\circ} \mathrm{C}$, unless otherwise specified. They concluded that drag reduction increased with increasing polymer concentration, and the concentration required for maximum drag reduction decreased with increasing polymer molecular weight. Finally, xanthan gum was found to be an appropriate drag reduction agent in the case of long-term applications and relatively high temperatures.

Another type of polysaccharide polymers guar gum in deionized water was employed to study the turbulent drag reduction efficiency in a rotating disk apparatus, and a linear correlation was obtained between polymer concentration and the concentration/(drag reduction) for diverse molecular weights of guar gum (C. A. Kim, Lim, Choi, Sohn \& Jhon, 2002). Three different molecular weights of guar gum such as unsonicated virgin guar gum (GGV), $30 \mathrm{~min}$ sonicated guar gum (GG30), and $60 \mathrm{~min}$ sonicated guar gum (GG60) were used. These molecular weights were obtained by the ultrasonic degradation method. The rotating disk apparatus specification was as previously reported (H. J. Choi et al., 1999; H. J. Choi et al., 2000; C. A. Kim et al., 1998; Sohn et al., 2001), and the drag reduction measurements were conducted at fixed rotational velocity of $1800 \mathrm{rpm}$, yielding a rotational Reynolds number of $9.6^{*} 10^{5}$. The guar gum stability with time was better than other water-soluble drag reducers [e.g., poly (ethylene oxide)], which means that it was more resistant to the mechanical stress than PEO.

Brostow, Lobland, Reddy, Singh \& White (2007) described the mechanical degradation of the drag reducing agent by measuring the drag reduction efficacy as a function of time and additives concentration. They used a grafting process to enhance the mechanical degradation resistance in turbulent flow conditions. This process included the grafting of one polymer on the backbone of other different polymers. A turbulent flow rheometer based on the classical design of Hoyt (J. W. Hoyt, 1975) was employed to determine the drag reduction rate. Input concentrations of the polymers varied from $50-5000 \mathrm{ppm}$. The results showed a high efficiency level of drag reduction for grafted polymer and the mechanical degradation rate was slower than the homopolymers degradation rate. Nonionic polyethylene oxide (PEO) in a synthetic saline solution was used to investigate the turbulent drag reduction characteristics in a rotating disk apparatus with a novel application to ocean thermal energy conversion technology (OTEC) (H. J. Choi et al., 2000). PEO was selected because of its excellent drag 
reduction abilities and high solubility in pure water (H. J. Choi \& Jhon, 1996). The molecular weight of the PEO samples ranged from $4.0^{*} 10^{5}$ to $5.0^{*} 10^{6} \mathrm{~g} / \mathrm{mol}$. The rotating disk apparatus comprised a cylindrical container $(16.3 \mathrm{~cm}$ diameter and $5.5 \mathrm{~cm}$ depth) and a stainless steel disk $(15.1 \mathrm{~cm}$ diameter and $0.32 \mathrm{~cm}$ thick) (C. A. Kim et al., 1997). The drag reduction measurements were performed at a specific value of rotational speed ranging from 1200-2000 rpm. Drag reduction increased with increasing polymer concentration at low concentrations, and when the concentration became quite high, the frictional drag increased due to increase of the solution viscosity. The maximum drag reduction obtained was $30 \%$ at $50 \mathrm{wppm}$ PEO and $\mathrm{Mw}=5.0^{*} 10^{6}$.

Yang, Choi, Kim \& Jhon, (1991), utilized poly ethylene oxide (PEO) and poly acrylamide (PAAM) in aqueous solutions as drag reducing agents using a rotating disk apparatus. The effects of various parameters such as angular disk velocity, temperature, polymer concentration, and polymer molecular weight on the drag reduction properties were also studied. Four different molecular weights of PEO, 40 000, 90 000, 4000 000, and 5000000 $\mathrm{g} /$ mole were used, and all experiments were performed at a fixed angular velocity of $2800 \mathrm{rpm}$. Drag reduction was seen to increase with increase of both polymer concentrations, reaching a maximum at its critical concentration, while at low polymer concentrations, polymers of higher molecular weight produce greater drag reduction. In addition, the drag reduction percentage was increased with increasing disk rotational speed for a certain time due to an increased rate of polymer degradation. Finally, they concluded that the mechanical degradation of PAAM was more stable at high temperatures than PEO.

J. H. Sung et al., (2004) used the same materials and apparatus in their previous work (Yang et al., 1991) with only two molecular weights $\left(5.5^{*} 10^{6}\right.$ and $\left.5.0^{*} 10^{6} \mathrm{~g} / \mathrm{mol}\right)$ of both PAAM and PEO. The effects of temperature, rotational speed, and polymer concentration on the drag reduction efficiency were investigated. In addition, the mechanical degradation rate in a turbulent flow was studied using both a fractional exponential decay and an exponential equation. The mechanical degradation rate of PEO increased dramatically with the increase in temperature, while PAAM remained stable even at high temperatures. Furthermore, relatively high shear resistance was exhibited by PAAM. Another two polymers were used to investigate their mechanical degradation behaviour using a rotating disk apparatus and the single exponential decay equation (H. J. Choi et al., 2000). Different degradation parameters were examined in this work, such as molecular weight, polymers concentrations, and molecular structure. Polyethylene oxide (PEO) with four molecular weights ranging from $4.0^{*} 10^{5}$ to $5.0^{*} 10^{6}$ and xanthan gum $(\mathrm{XG})$ were employed as drag reduction additives. The RDA used here was similar to other experiments (C. A. Kim et al., 1998; C. A. Kim et al., 1999). It was summarized that the single exponential decay model was only valid for polymers resistant to shear degradation and was not universally acceptable for all drag reduction degradation behaviour in turbulent flow.

The turbulent drag reduction characteristics of polyethylene oxide (PEO) (Mw $=4.0 \times 10^{6} \mathrm{~g} / \mathrm{mol}$ ) in aqueous solutions of sodium acetate $\left(\mathrm{CH}_{3} \mathrm{COONa}\right)$ at several distances $\tau \equiv\left(\mathrm{T}_{\theta}-\mathrm{T}\right) / \mathrm{T}_{\theta}$ away from the theta temperature $\left(\mathrm{T}_{\theta}\right)$ were investigated (S. T. Lim, Hong, Choi, Lai, \& Chan, 2007). Three different concentrations $(0.75 \mathrm{M}, 1.5$ $\mathrm{M}$, and $2.0 \mathrm{M})$ of sodium acetate $\left(\mathrm{CH}_{3} \mathrm{COONa}\right)$ were used to prepare these aqueous solutions. The drag reduction percentage decayed faster for systems nearer to the theta point, which means that only the long-term behaviour of the $\% \mathrm{DR}$ of the system is sensitive to $\tau$. This faster decay was attributed to the faster mechanical molecular degradation (MMD) of polymers in bad solvents produced by turbulence. In addition, the DR properties of a polymer were sensitive to the conformation of the polymers controlled by the distance away from $T_{\theta}$ even at very low polymer concentrations.

Different types of DNA were used as drag reduction additives (S. T. Lim, Choi, Lee, So \& Chan, 2003; S. T. Lim, Park, Chan $\&$ Choi, 2005). A monodispersed high molecular weight $\lambda$-DNA was utilized using a buffer solution under a turbulent flow to investigate the turbulent drag reduction characteristics in a rotating disk apparatus, and compared with polyacrylamide (PAAM) (S. T. Lim et al., 2003). In addition, the mechanical degradation of $\lambda$-DNA was studied with different values of the disk rotational speed. Increase of the rotational speed was performed using two modes: a continuous and stepwise mode. Due to the mechanical degradation of $\lambda$-DNA, a midpoint scission of the long chain molecules was indicated. Using the same rotating disk apparatus as in their previous work (S. T. Lim et al., 2003), another type of DNA (polydisperse calf-thymus DNA) (CT-DNA) in a buffer solution was employed to investigate its turbulent drag reduction behaviours and compare it with monodisperse $\lambda$-DNA (S. T. Lim et al., 2005). The calf-thymus DNA has a higher molecular weight and different structural characteristics compared with monodisperse $\lambda$-DNA. Since DNAs have a unique molecular structure (helical structure) compared to conventional flexible polymeric drag reducers (usually linear flexible structure), we could expect that this characteristic will make it possible to show a more detailed understanding in the DR experiment and analysis. For example, (Hand \& Williams, 1970) measured drag reducing phenomena of CT-DNA as a function of $\mathrm{pH}$ and observed that the less flexible helical conformation is preferable to the random 
coil for maximum DR. It was observed that the calf-thymus DNA is more susceptible to mechanical degradation in a turbulent flow because its chains have a much higher molecular size than that of $\lambda$-DNA.

A new procedure was used to enhance the mechanical degradation resistance of polymers and their drag reduction efficiency by adding a minute amount of surfactant to them. For example, (J. T. Kim et al., 2011) examined the drag reduction efficiency of ionic poly (acrylic acid) and sodium dodecyl sulfate (SDS) complex system under a turbulent flow in a rotating disk apparatus. The dependence of the drag reduction on several parameters such as concentration, rotating speed, surfactant, and $\mathrm{pH}$ was also investigated. Three different molecular weights of PAAM $\left(4.5 \times 10^{5}, 7.5 \times 10^{5}\right.$ and $\left.12.5 \times 10^{5} \mathrm{~g} / \mathrm{mol}\right)$ were used as drag reducing additives. They concluded that the drag reduction percentage increases with the increase of rotational speed, implying that the complex interactions between the polymer and the surfactant molecules play a critical role. The maximum drag reduction efficiency was observed at a polymer concentration of $150 \mathrm{ppm}$, as shown in Figure 18.

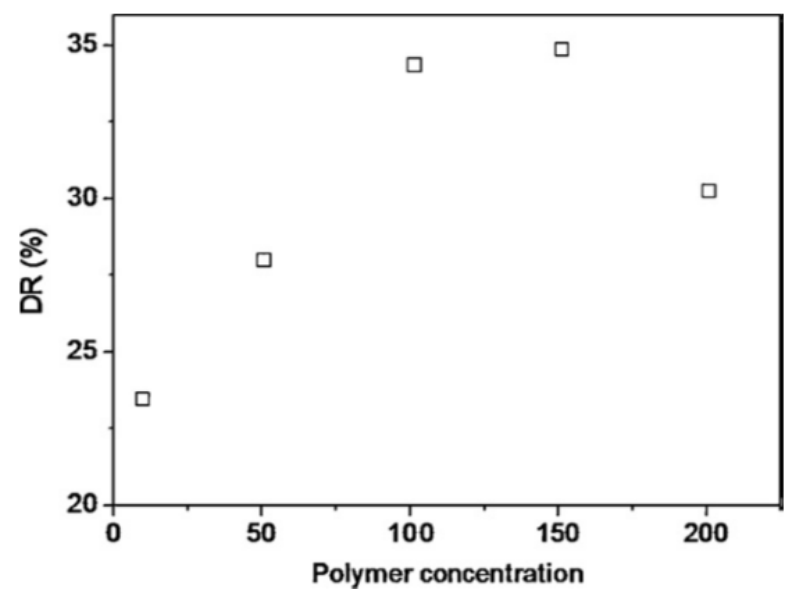

Figure 18. Drag reduction as a function of polymer concentration at $0.008 \mathrm{M}$ SDS $(\mathrm{pH}$

11) (J. T. Kim et al., 2011)

H. J. Choi and Jhon (1996) investigated the effect of polyethylene oxide (PEO) (water-soluble) and polyisobutylene (PIB) (oil-soluble) on drag reduction efficiency under turbulent flow by a rotating disk apparatus, and created a linear correlation between the drag reduction for different molecular weights of PEO and PIB polymer concentration. Four different molecular weights of PIB (L-80, L-100, L-120, and L-140) and four different molecular weights of PEO (ranging from $4.0^{*} 10^{5}$ to $5.0^{*} 10^{6}$ ) were used as drag-reducing additives with kerosene and water as a solvent, respectively. The rotating disk apparatus used in this work comprised a stainless steel cylindrical thermostatically controlled container $(16.3 \mathrm{~cm}$ inside diameter $\times 5.5 \mathrm{~cm}$ height $)$ and a stainless steel disk $(10.1 \mathrm{~cm}$ diameter $\times 0.32 \mathrm{~cm}$ thickness $)$. The volume of solution required to fill the entire container was about $1020 \mathrm{~cm}^{3}$ and all RDA measurements were above $1050 \mathrm{rpm}$. It was noticed that the drag reduction increases with increasing polymer solution concentration until the optimum concentration, and then the percentage of drag reduction decreases with concentrations greater than the optimum concentration. In addition, at low concentrations a maximum drag reduction was shown with high molecular weight polymers.

The drag reduction characteristics of aqueous solutions of poly (ethylene oxide), poly (acrylamide), hydrolyzed poly (acrylamide), and poly (acrylic acid) were examined using a rotating disk apparatus. The drag reduction efficiency for these polymers was calculated and compared with those obtained from two pipe flow systems. The rotating disk system comprised a Lucite container ( 9 inch diameter $\times 5$ inch height) and a stainless steel disk (4.25 inch diameter) which was rotated by a DC electric motor provided with a constant speed control unit. The percentage of drag reduction increases rapidly with polymer concentration and reaches a saturation level at only a few parts per million, and it was found to obey the universal drag reduction relationship (Little, Patterson \& Ting, 1976).

Polysaccharide guar gum (GG) was examined by (C. H. Hong, Zhang, Choi \& Yoon, 2010) as a drag reduction additive and they investigated the mechanical degradation of this polymer under turbulent flow using a rotating disk apparatus as a function of time. Two diverse degradation models of a single relaxation process and a stretched-exponential model were used to correlate the time-dependent drag reduction and mechanical 
degradation of GG. The ultrasonic technique was employed to produce three samples with different molecular weights of GG, such as unsonicated virgin guar gum (GGV), guar gum ultrasonicated for $30 \mathrm{~min}$ (GG30), and guar gum ultrasonicated for $60 \mathrm{~min}$ (GG60). The rotating disk apparatus employed in this study was the same as previously used in (C. A. Kim et al., 2002; S. T. Lim et al., 2002). It was found that the stretched-exponential equation, Equation 3, described the degradation mode better than a single relaxation process.

$$
\frac{D R(t)}{D R_{o}}=\exp \left[-\left(\frac{t}{\lambda_{2}}\right)^{1-n}\right]
$$

The effect of adding sodium salicylate nanoparticles to a complex of xanthan gum polymer with hexadecyltrimethyl ammonium chloride surfactant on the drag reduction efficacy was investigated using a rotating disk apparatus (RDA) (Akindoyo, Abdulbari \& Yousif, 2015). This apparatus comprised a stainless steel solution container (165 mm diameter and $88 \mathrm{~mm}$ height), a smooth stainless steel disk of about $3 \mathrm{~mm}$ thickness and $148 \mathrm{~mm}$ in diameter, and a computer display system to record torque measurements and control the angular velocity of the disk. The maximum solution container capacity and operated rotational disk speed were $1200 \mathrm{ml}$ and $3000 \mathrm{rpm}$, respectively. Both complexes and nanofluid were able to reduce the drag. The mechanical stability and drag reduction were better with the three-dimensional complex (with silica nanoparticles) than the two-dimensional complex (without nanoparticles). The maximum drag reduction was $60 \%$ at different concentrations and working approaches.

Another polymer-surfactant complex of polyacrylamide-co-diallyl dimethylammonium chloride (PAMC) (anionic polymer) and Tween 20 (nonionic surfactant) in aqueous solution was used to examine their effects on the drag reduction percentage and mechanism degradation performance using rheology, rotating disk apparatus (RDA) and pipe loop techniques (Bari \& Faraj, 2015). In addition, the influence of rotational speed, surfactant concentration and polymer concentration in improving the drag reduction was investigated. Different concentrations $(50,500,700$ and $1000 \mathrm{ppm})$ of samples from the polymer-surfactant blend were prepared using $200 \mathrm{ml}$ of deionized water. All RDA experiments were conducted by varying the rotational velocity from 50 $3000 \mathrm{rpm}$, with constant temperature $\left(25{ }^{\circ} \mathrm{C} \pm 0.05{ }^{\circ} \mathrm{C}\right)$. The experimental results showed that a $35 \%$ drag reduction can be obtained, and the drag reduction efficiency of the PAMC-Tween mixture was found to be better than that of pure PAMC.

A new water-soluble copolymers poly(acrylamide-co-acrylic acid) ( $\mathrm{Mw}=5000000 \mathrm{~g} / \mathrm{mol}$ ) was used to improve the drag reduction properties of turbulent flow using a rotating disk apparatus, and the influence of experimental parameters such as the rotational speed of the disk, polymer concentration, and temperature on these properties was studied (Zhang, Choi \& Jang, 2011). The specifications of the RDA have been previously reported (S. T. Lim et al., 2003). Five different concentrations of copolymer solution (10, 30, 50, 100, and $200 \mathrm{ppm})$ were used at $80^{\circ} \mathrm{C}$ with an angular velocity of $1980 \mathrm{rpm}$. The mechanical degradation rate of the copolymers was increased with increase of the solution temperature, indicating that polymer chain scission becomes more severe at high temperatures. The maximum drag reduction was $45 \%$ at $50 \mathrm{ppm}$ of dilute copolymer solution injected into the RDA. The turbulent drag reduction in a the rotating disk apparatus (RDA) was examined using two water-soluble polymers poly (ethylene oxide) $(\mathrm{PEO})(\mathrm{Mw}=8000000)$ and poly (acryl amide) (PAAM) $(\mathrm{Mw}=18$ 000000 ), as a function of temperature and polymer concentration (C. H. Hong et al., 2008). They also analyzed the mechanical degradation behaviour of these polymers using both a fractional exponential decay equation and a simple exponential decay function, and the RDA which is the same as previously described (H. J. Choi \& Jhon, 1996). The drag reduction results of PEO were $25.54 \%, 30.09 \%$, and $33.42 \%$ at a constant concentration of 2.5 , 5 , and $10 \mathrm{ppm}$, respectively, while for the same fixed concentration of PAAM, the results were $30.12 \%, 33.98 \%$, and $36.53 \%$, respectively, as shown in Figure 19. In the case of PEO, the experimental data was fitted with the fractional exponential decay equation better than the simple first-order degradation exponential decay function.

In their previous work (J. H. Sung, Lim, Kim, Chung \& Choi, 2004), the same rotating disk apparatus was used to study the effects of two different molecular weights of water soluble PEO $\left(4.0^{*} 10^{6}\right.$ and $\left.5.0^{*} 10^{6} \mathrm{~g} / \mathrm{mol}\right)$ on the turbulent drag reduction efficacy as a function of temperature and polymer concentration. The mechanical degradation rate was also examined using both a fractional exponential decay equation and a simple exponential decay function. All experiments were conducted at a constant angular velocity of $2800 \mathrm{rpm}$, with $\mathrm{Re}=8.3^{*} 10^{5}$. The drag reduction effectiveness of lower molecular weight was less than that of higher molecular weight at polymer concentrations up to $250 \mathrm{wppm}$ and $2800 \mathrm{rpm}$. In addition, the lower molecular weight polymer showed more mechanical degradation than that of higher molecular weight polymers; and the mechanical degradation rate of the polymer increased with increasing solution temperature. The fractional exponential decay equation was found to fit the experimental data better than the simple exponential decay function. 


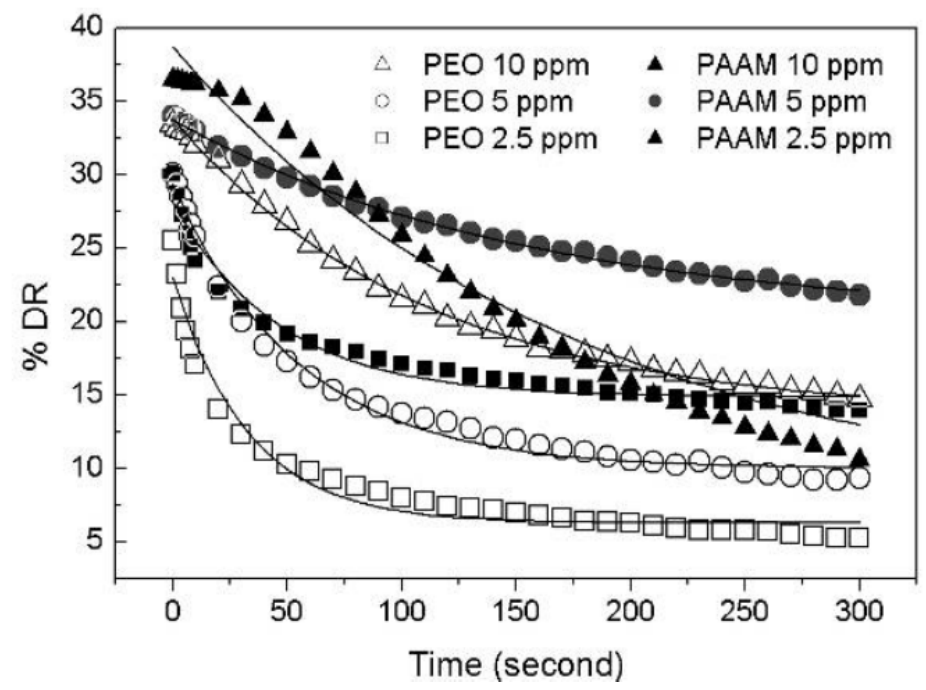

Figure 19. $\%$ DR as a function of time for PEO and PAAM in solution at different concentrations, $25{ }^{\circ} \mathrm{C}$. Solid line represents values obtained from Eq. (2), and points represent experimental data (C. H. Hong et al., 2008)

Polyisobutylene (PIB) (oil-soluble polymer) showed a significant drag reduction when added to turbulent flow of kerosene by a rotating disk in a closed chamber (S. T. Lim et al., 2002). The authors studied the turbulent drag reduction produced by polyisobutylene suspended in kerosene and its mechanical degradation under a turbulent flow. The specifications of the RDA comprised a stainless steel disk with a diameter of $14.5 \mathrm{~cm}$ and a thickness of $0.32 \mathrm{~cm}$ (H. J. Choi \& Jhon, 1996; C. A. Kim et al., 1997). Four different molecular weights of PIB, L-80 $\left(\mathrm{Mw}=1.60 \times 10^{6} \mathrm{~g} / \mathrm{mol}\right), \mathrm{L}-100\left(\mathrm{Mw}=1.86 \times 10^{6} \mathrm{~g} / \mathrm{mol}\right), \mathrm{L}-120\left(\mathrm{Mw}=2.06 \times 10^{6} \mathrm{~g} / \mathrm{mol}\right)$ and L-140 $(\mathrm{Mw}=$ $\left.2.52 \times 10^{6} \mathrm{~g} / \mathrm{mol}\right)$, were utilized. It was found that the drag reduction efficacy reduced with time due to mechanical degradation of the polyisobutylene chains, and increased with increasing PIB concentration up to an optimal concentration. However, higher molecular weight polymers show a maximum drag reduction at lower concentrations. Maximum \%DR was found at 300 wppm for both L-120 and L-140 and at 400 wppm for L-100, as shown in Figure 20. Using the same equipment and materials as in this study, (K. Lee et al., 2002) studied the turbulent drag reduction and mechanical molecular degradation of polyisobutylene in kerosene using a rotating disk apparatus, and calculated the relationship between this molecular degradation and the molecular weight distribution (MWD) curve. The amount of degradation and the DR efficacy were fitted to an exponential function and then compared with molecular weights measured by size-exclusion chromatography. The polyisobutylene sample used in this work was PIB L-140 with Mw of $2.52 * 10^{6} \mathrm{~g} / \mathrm{mol}$. The DR percentage decreased with time due to the mechanical molecular degradation of the polyisobutylene, and an excellent correlation between this percentage and the molecular weight or the MWD over time was noticed.

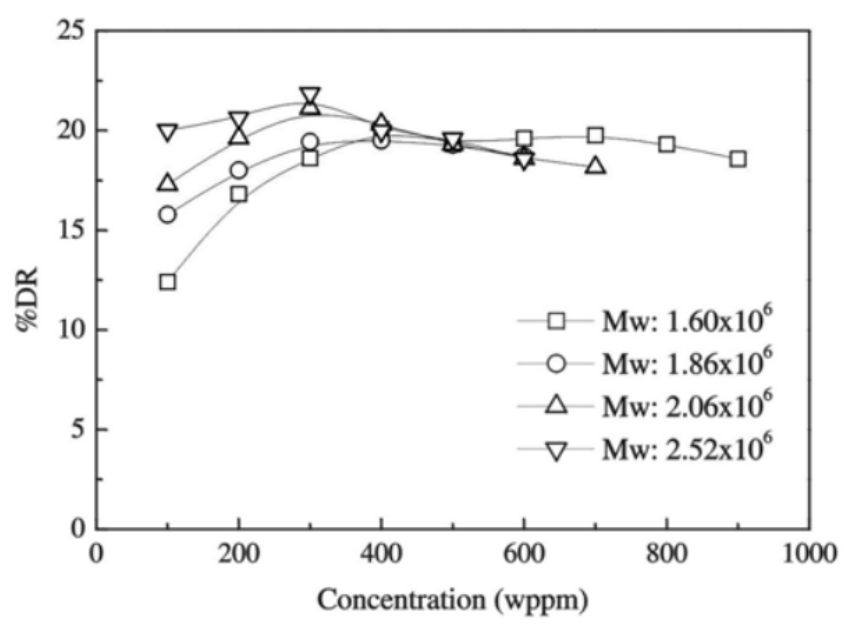

Figure 20. \%DR vs. PIB concentrations for four different molecular weights at $1800 \mathrm{rpm}$ (S. T. Lim et al., 2002) 
As in their previous study, (K. H. Lee, Zhang \& Choi, 2010) investigated the effect of numerous parameters such as Reynolds number (Re), temperature of PIB-kerosene solution, and molecular weight on drag reduction. In addition, the change in drag reduction efficacy was fitted well with two model equations of Brostow and their suggested model as a function of time. Four different molecular weights of PIB, L-80 (Mw $=808000 \mathrm{~g} / \mathrm{mol}$ ), L-100 (Mw = $996000 \mathrm{~g} / \mathrm{mol}), \mathrm{L}-120(\mathrm{Mw}=1075000 \mathrm{~g} / \mathrm{mol})$ and L-140 (Mw = $1122000 \mathrm{~g} / \mathrm{mol})$, were employed. The drag reduction declined faster at higher temperature than at lower temperature, and the turbulent drag reduction efficiency for the PIB-kerosene solution decreased with time due to mechanical degradation of the polymer chains.

Using the same polymer additives and solvent fluid, (C. A. Kim et al., 1997) studied the capability of using polyisobutylene (PIB) to improve the drag reduction properties of kerosene in a rotating disk apparatus. Four different molecular weight ranges of PIB $9.9 \times 10^{5}$ (L-80), $1.2 \times 10^{6}(\mathrm{~L}-100), 1.6 \times 10^{6}(\mathrm{~L}-120)$ and $2.1 \times 10^{6}$ (L-140) were used, and all data were measured at a fixed rotational speed of $1600 \mathrm{rpm}$. The intrinsic concentration [C] was found to be an extremely useful quantity in normalizing the drag reduction data for different molecular weights of PIB and concentrations similar to polyethylene oxide (PEO) in water. In order to investigate the drag reduction efficiency of an aqueous solution of potassium chloride $(\mathrm{KCl})$, a small amount of xanthan gum $(\mathrm{XG})$ was added. In addition, the influences of the experimental parameters such as time, $\mathrm{KCl}$ concentrations, and XG concentrations on this efficiency were studied in a rotating disk apparatus (C. H. Hong, Choi, Zhang, Renou, \& Grisel, 2015). The RDA container was filled with a solution volume of $370 \mathrm{ml}$ containing 10, 50, 100 and $200 \mathrm{ppm}$ XG with different concentrations of $\mathrm{KCl}(0 \mathrm{M}, 0.01 \mathrm{M}$ and $0.1 \mathrm{M})$, respectively. The xanthan gum's drag reduction efficacy decreased with increasing potassium chloride concentration, and the time-dependent DR efficiency was found to be fitted well using the Brostow model equation. At higher $\mathrm{KCl}$ concentrations, the chain degradation behaviour decreased with time, while at higher $\mathrm{XG}$ concentrations, the drag reduction percentage increased.

H. J. Choi et al. (2002) studied the turbulent drag reduction induced by $\lambda$-DNA and compared it with a high molecular weight polyethylene oxide (PEO) $\left(\mathrm{Mw}=5 * 10^{6}\right)$ using rotating disk apparatus (RDA). Moreover, the transient behaviour of the mechanical molecular degradation (MMD) of DNA chains in a turbulent flow was investigated. The present RDA was previously used in (C. A. Kim et al., 2000). They concluded that double-stranded DNA (dsDNA) was a good drag reducer when compared with the other normal linear polymers, and its mechanical degradation was also different from these normal polymers. Their results indicated that the mechanism for turbulent degradation of DNA is different from that of the normal flexible long-chain polymers. However, it has to be mentioned that the stronger resistance of dsDNA to MMD does not mean that dsDNA is a more efficient drag reducer than other normal linear polymers. The turbulent drag reduction characteristics and shear stability of amylopectin (AP) and its grafted derivative (GA) were studied by (S. T. Lim et al., 2004) in a rotating disk apparatus. The influence of various experimental parameters such as rotation speed, temperature, and polymer concentration on the drag reduction characteristics was also investigated. Specifications of the RDA have been previously reported (C. A. Kim et al., 2000). It has been remarked that temperature, polymer molecular weight, solvent quality, Reynolds number, and polymer concentration are the significant parameters that can influence the turbulent drag reduction characteristics by polymeric additives. GA revealed a very strong shear resistance and relatively high DR (27\%) compared to AP. High molecular weight polystyrene (PS) was employed as an additive for three different solvents (benzene, chloroform, and toluene) to investigate the influence of the solvent on both the drag reduction characteristics and the mechanical degradation of the additives using a rotating disk apparatus at a turbulent flow system (C. A Kim et al., 2000). The specifications of the RDA have been previously reported (C. A. Kim et al., 1997; C. A. Kim et al., 1998). A theoretical model for molecular degradation in turbulent flow suggested by (W. Brostow et al., 1990) was adopted for experimental data and an excellent fit was gained. It was indicated that the DR declines with time due to the degradation of the polymer molecules under turbulent flow, as shown in Figure 21. 


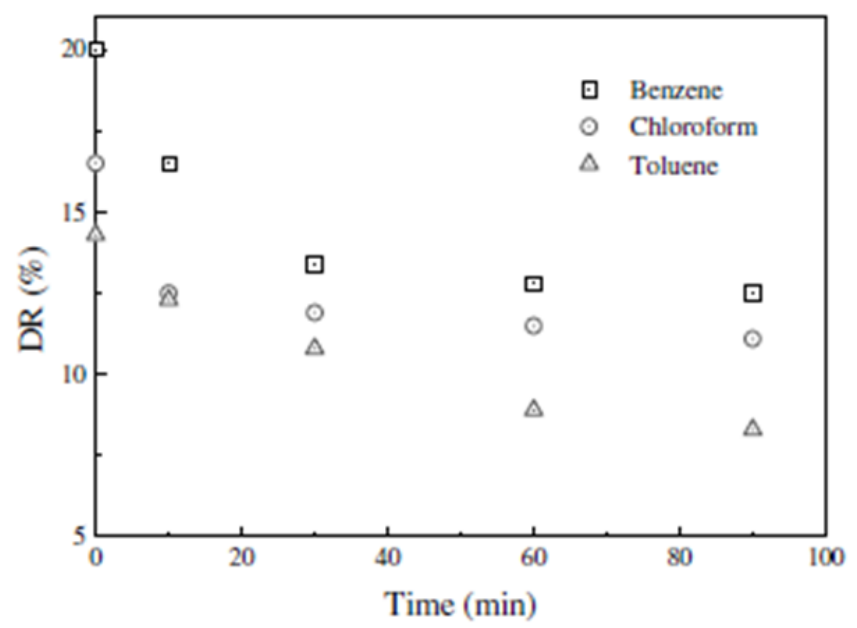

Figure 21. Percent DR vs. time for PS in three different solvents (150 ppm) (C. A Kim et al., 2000)

A novel complex system of anionic polymer (polyacrylamide) (PAM) and anionic surfactant (Triton X-45) was introduced by (Bari, Yousif \& Akindoyo, 2015) to improve the polymer degradation resistance in turbulent drag reduction systems. The polymer and surfactant were examined individually and as a complex using a rotating disk apparatus (RDA) and a Brookfield viscometer with different concentrations and rotational velocity (rpm) of the disk. The polymer and surfactant concentrations were 500,1000, 1500 and $2000 \mathrm{ppm}$, and the rotational velocity ranged from 50-3000 $\mathrm{rpm}$. To investigate the stability of the polymer and surfactant additives, the torque was measured with time at a constant rotational speed. It was found that both the PAM and Triton X-45 have a stable shear stress as drag-reducing agents, particularly with concentrations above $1000 \mathrm{ppm}$, and the optimum shear stability was found with a concentration of $2000 \mathrm{ppm}$ as shown in Figs. 22 and 23. It could be seen that the drag reduction efficiency of the complex mixture was better than their individual efficiency. The maximum drag reduction percentage was $60 \%$ at a complex concentration of $1000 \mathrm{ppm}$ for polymer and surfactant, respectively.

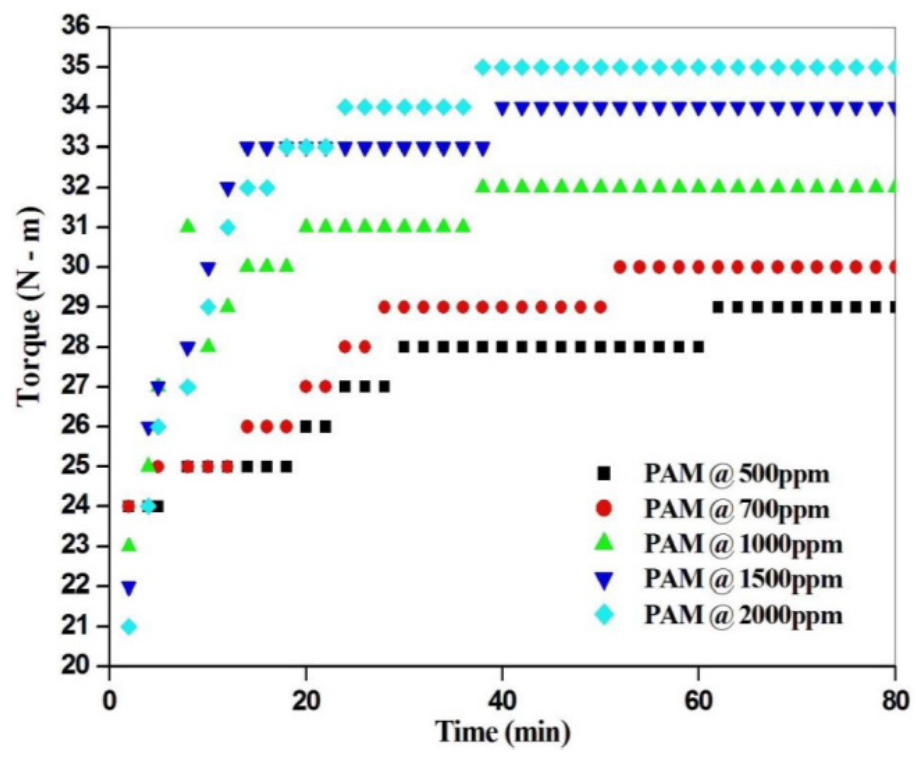

Figure 22. Time-dependence torque values for PAM were studied with five different concentrations as a function of time, at $3000 \mathrm{rpm}$ and $25^{\circ} \mathrm{C}$ (Bari et al., 2015) 


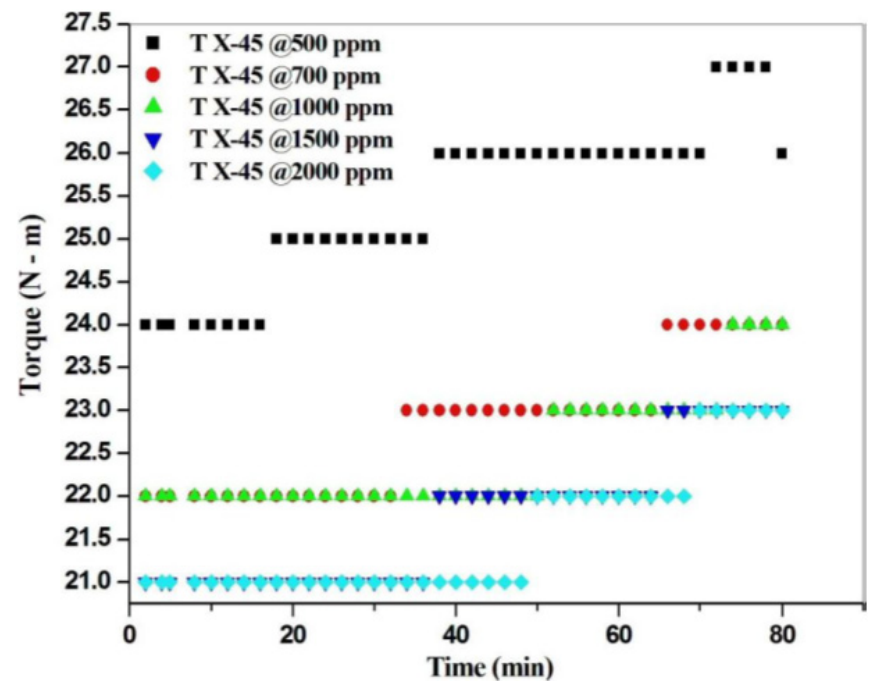

Figure 23. Time-dependence torque values for Triton X-45 were studied with five different concentrations as a function of time, at $3000 \mathrm{rpm}$ and $25^{\circ} \mathrm{C}$ (Bari et al., 2015)

Polyethylene glycol was utilized as a drag reducing agent with two different solvents (distilled water and glycerol) at different concentrations by a rotating disk apparatus (Figure 24) (Jafargholinejad, Pishevar \& Sadeghy, 2011). Their results showed that this polymer can reduce skin friction under turbulent flow conditions, while it has no effect on Taylor instabilities. The maximum drag reduction achieved was $10 \%$, and the $\% \mathrm{DR}$ increased with increasing Reynolds number.

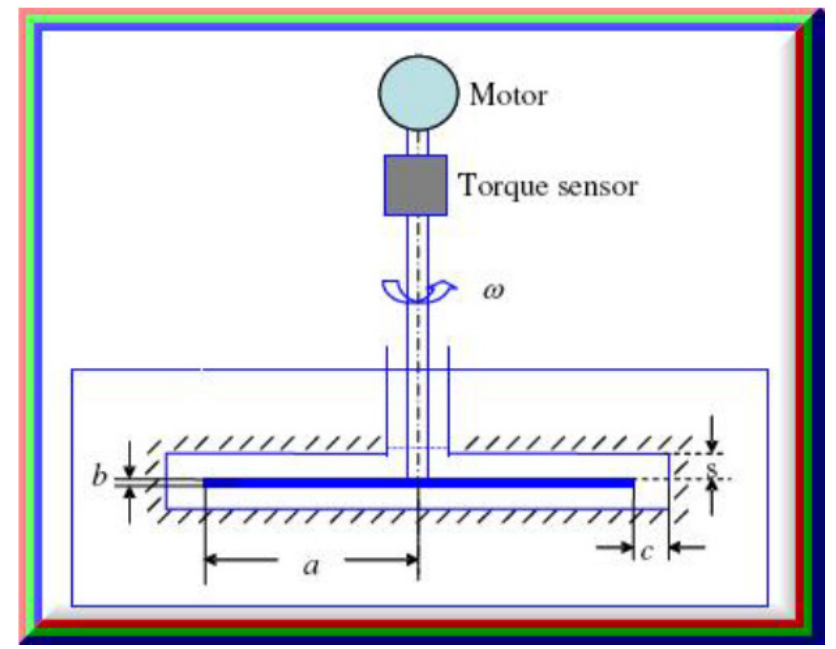

Figure 24. Schematic of rotating disk apparatus (Jafargholinejad et al., 2011)

L. A. Bernardez (2009) studied the biodegradation of polycyclic aromatic hydrocarbons (PAHs) (naphthalene and phenanthrene) in a nonionic surfactant solution of Brij 35 using a rotating disk apparatus, and demonstrated a relationship between the biodegradation rate and surfactant amount and the mechanisms controlling the mass transfer of PAH from non-aqueous phase liquid (NAPLs). A $250 \mathrm{ml}$ liquid solution was used for a pure mineral solution or a mineral solution with surfactant. The measuring techniques, experimental apparatus, and materials for the dissolution process were previously reported (L. A. Bernardez \& Ghoshal, 2004, 2008; L. A. Bernardez, 2008a, 2008b). (Imayama, Alfredsson \& Lingwood, 2011) measured the laminar-turbulent transitional region of the rotating disk boundary layer using a rotating disk shown in Figure 25. They recorded the flow regimes from the stable laminar flow region, through the unstable and transitional regions, into the fully turbulent region. The disk was made of glass with a thickness of $24 \mathrm{~mm}$ and a diameter of $474 \mathrm{~mm}$ and was mounted on the original aluminium alloy disk. This aluminium disk was connected to a DC servomotor through an iron disk and a 
vertical shaft.

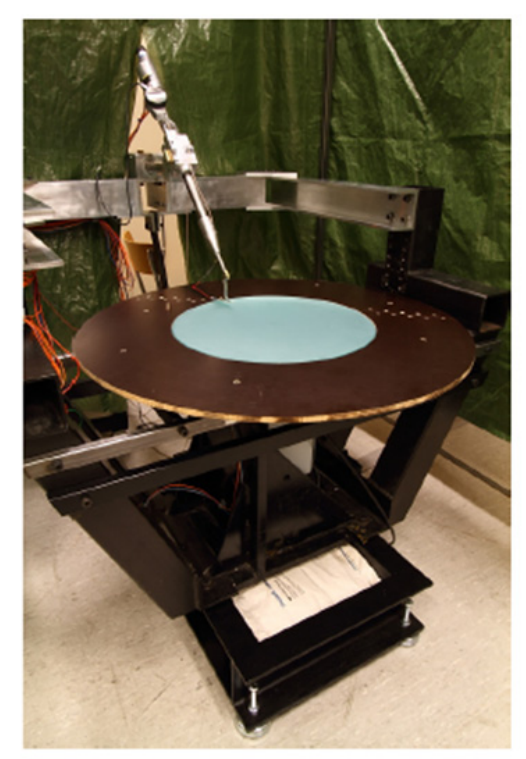

Figure 25. The experimental set-up of the rotating disk

Vatankhah, Jafargholinejad and Mozaffarinia (2011) studied the effect of two diverse hydrophobic polymer coatings: i) Poly-tetra fluoro ethylene (PTFE) and ii) room temperature vulcanized (RTV) silicon rubber, on the drag reduction properties using a rotating disk apparatus (RDA).These coatings were coated on an aluminium disk surface with 0.1 and $0.4 \mathrm{~mm}$ thickness of RTV silicon rubber and 0.2 and $0.4 \mathrm{~mm}$ of PTFE. The RDA used in this work comprised an aluminium disk with a radius of $7 \mathrm{~cm}$ and thickness of $0.3 \mathrm{~cm}$. This disk was rotated at a constant rotational speed $(0-2000 \mathrm{rpm})$ by the rotor system in a liquid container $18 \mathrm{~cm}$ in diameter and $1.9 \mathrm{~cm}$ high. The rotor system was provided with a torque sensor having a capacity of $200 \mathrm{~N}$. cm and an accuracy of 0.1 N.cm, as demonstrated in Figure 26. It was concluded that PTFE was more effective than RTV in reducing the drag forces of fluids, where the achieved drag reduction percentage was $18 \%$ and $11 \%$ with PTFE and RTV silicon, respectively. In addition, they observed that the drag reduction efficacy of the coatings used decreased with increasing Reynolds number.

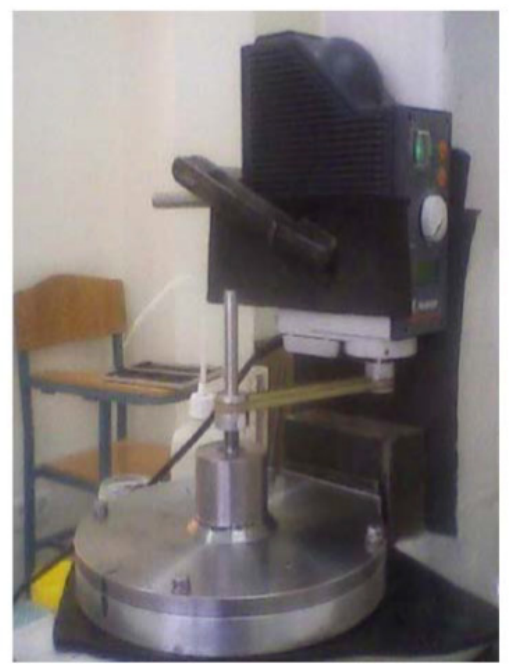

Figure 26. Fabricated rotating disk dimensional details (Vatankhah et al., 2011) 
Experimentally, a new type of Newtonian fluid drag reduction for a rotating disk was clarified using a highly water-repellent coating wall and compared with a smooth aluminium wall (K. Watanabe \& Ogata, 1998). Various values of the clearance between the housing wall and the disk $(5,10$, and $20 \mathrm{~mm}$ thick) were used with a clearance ratio of $(\mathrm{s} / \mathrm{a})=0.055,0.111$, and 0.222 . The fluids tested were $30 \mathrm{wt} \%$ and $40 \mathrm{wt} \%$ aqueous solution of glycerin and tap water. Firstly, an aluminium smooth disk with $180 \mathrm{~mm}$ diameter and $3 \mathrm{~mm}$ thickness was used and then one side of this disk was coated with a $5 \mu \mathrm{m}$ film of highly water-repellent material. Figure 27 shows the experimental apparatus. The moment values of the coated rotating disk decreased compared with the values of the aluminium smooth disk. The maximum drag reduction ratio obtained was about $45 \%$ at $40 \mathrm{wt} \%$ concentration of glycerin aqueous solution.

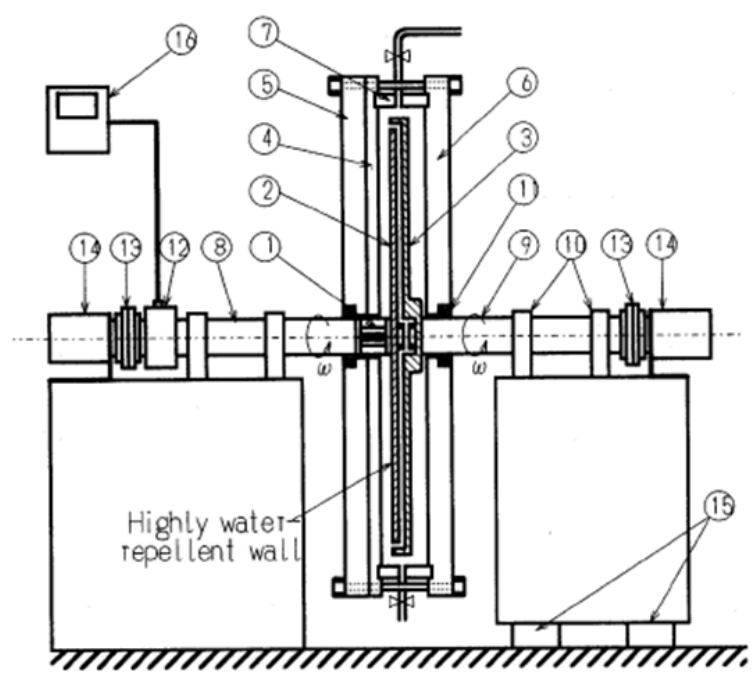

(1) Torque measurement deviøe
(2) Rotat ing disk
(3) Support disk
(4) Spacer
(5) Side plate 1
(b) Side plate 2
(7) Housing
(8) Shaft 1

(9) Shaft 2

(10) Bear ing units

(11) Oil seals

(12) Slipring

(13) Coupling

(14) DC motor

(11) Sliding unit

(16) Strain meter

Figure 27. Experimental apparatus (K. Watanabe \& Ogata, 1998)

Another type of drag reduction with fine spiral grooves was adopted by (K. Watanabe, Budiarso, Ogata \& Uemura, 2005) to reduce the skin friction of the impeller of a turbo machine and to clarify the mechanism of the drag reduction phenomenon using a flow visualization technique and velocity profile measurements. The rotating disk apparatus used in this work is previously used by (K. Watanabe \& Ogata, 1998). These spiral grooves were made by a wet etching process with a height range of 100-200 $\mu \mathrm{m}$, and 120-160 grooves. Numerous kinds of disks were prepared to study the effect of the height (h), flow angle $(\phi)$, and number (n) of the grooves. The Reynolds number ranged from $4 * 10^{4}-6 * 10^{5}$. The test fluids were tap water, and aqueous solutions of glycerin with concentrations of 20 and $30 \mathrm{wt} \%$. The rotating test disk was fabricated from aluminium with $180 \mathrm{~mm}$ diameter and $3 \mathrm{~mm}$ thickness. All experiments were performed with different axial clearance between the disk and the stationary circular end wall $(\mathrm{s} / \mathrm{a}=0.011,0.033,0.11,0.22$, and 0.33$)$. The maximum drag reduction ratio achieved was roughly $15 \%$, and it was seen that this percentage depended on the depth, the spiral angle, and the number of grooves. The most effective drag reduction was obtained with $\mathrm{n}=150$, and $\mathrm{h}=0.1 \mathrm{~mm}$, and no drag reduction occurred with $\mathrm{n}=160$.

\section{Conclusion}

Different applications of rotating disk apparatus and the effect of numerous parameters on these applications were discussed in this study. The rotating disk apparatus has been used not only in drag reduction applications, but also in the electrodeposition process as an electrode and in solid-liquid reactions as rotating reactor. It can be concluded that there are many types of rotating disk apparatus depending on their use. For example, a rotating 
ring disk electrode (RRDE-3A) was used to study the effect of the electrocatalyst properties on the oxygen reduction reaction (ORR), and the rotating disk-slurry electrode (RODSE) system was utilized to describe the large-scale production of well dispersed Pt nanoparticles on unsupported carbon black. The rotating disk acid reaction system (CRS-100) is one of the main types of rotating disk reactor, which was employed to calculate rock/acid reaction rates. Furthermore, the production of nanoparticles using a rotating disk reactor (RDR) has been proposed for the production of several compounds. We can observe from previous studies on drag reduction in a rotating disk apparatus that most of them focused on active drag reduction through the addition of drag-reducing agents which include polymers, surfactants, and complex mixtures of both of them. The passive drag reduction procedure was not studied as extensively as the active drag reduction. Two studies only used the coated rotating disk and coated cylinder with spiral groove and water-repellent coating, respectively, and no-one used the structured disk surface with different types and dimensions of riblets. Therefore, the rotating disk apparatus is highly recommended to investigate the effect of different riblets types and dimensions on drag reduction performance with high range of Reynolds number.

\section{Acknowledgments}

I wish to express my deepest appreciation to my supervisory committee for their guidance, advice, criticism, encouragements and insight throughout this research.

\section{References}

Abdulbari, H. A., Shabirin, A., \& Abdurrahman, H. N. (2013). Bio-polymers for improving liquid flow in pipelines-A review and future work opportunities. Journal of Industrial and Engineering Chemistry, 20(4), 1157-1170. http://dx.doi.org/10.1016/j.jiec.2013.07.050

Abdulbari, H. A., Yunus, R. M., Abdurahman, N. H., \& Charles, A. (2013). Going against the flow-A review of non-additive means of drag reduction. Journal of Industrial and Engineering Chemistry, 19(1), 27-36. http://dx.doi.org/10.1016/j.jiec.2012.07.023

Akindoyo, E. O., Abdulbari, H. A., \& Yousif, Z. (2015). A dual mechanism of the drag reduction by rigid polymers and cationic surfactant: complex and nanofluids of xanthan gum and hexadecyl trimethyl ammonium chloride. International Journal of Research in Engineering and Technology, 4(2), 84-93.

Al-Sarkhi, A. (2010). Drag reduction with polymers in gas-liquid/liquid-liquid flows in pipes: A literature review. Journal of Natural Gas Science and Engineering, 2(1), 41-48. http://dx.doi.org/10.1016/j.jngse.2010.01.001

Al-Sarkhi, A., \& Hanratty, T. J. (2001). Effect of drag-reducing polymers on annular gas-liquid flow in a horizontal pipe. International Journal of Multiphase Flow, 27(7), 1151-1162. http://dx.doi.org/10.1016/S0301-9322(00)00071-9

Al-Sarkhi, A., \& Hanratty, T. J. (2002). Effect of pipe diameter on the drop size in a horizontal annular gas-liquid flow. International Journal of Multiphase Flow, 28(10), 1617-1629. http://dx.doi.org/10.1016/S0301-9322(02)00048-4

Al-Sarkhi, A., Abu-Nada, E., \& Batayneh, M. (2006). Effect of drag reducing polymer on air-water annular flow in an inclined pipe. International Journal of Multiphase Flow, 32(8), 926-934. http://dx.doi.org/10.1016/j.ijmultiphaseflow.2006.03.001

Al-sarkhi, A., Nakla, M. El, \& Ahmed, W. H. (2011). Friction factor correlations for gas-liquid/liquid-liquid flows with drag-reducing polymers in horizontal pipes. International Journal of Multiphase Flow, 37(5), 501-506. http://dx.doi.org/10.1016/j.ijmultiphaseflow.2011.01.005

Amidon, L. G., Lee, P. I., \& Topp, E. M. (2000). Transport Processes in Pharmaceutical Systems. New York: Marcel Dekker.

Antileo, C., Roeckel, M., \& Wiesmann, U. (2003). High nitrite buildup during nitrification in a rotating disk reactor. Water Environment Research : A Research Publication of the Water Environment Federation, 75(2), 151-162. http://dx.doi.org/10.2175/106143003X140935

Armstrong, R., \& Jhon, M. S. (1984). A Self-Consistent Theoretical Approach To Polymer Induced Turbulent Drag Reduction. Chemical Engineering Communications, 30(1-2), 99-111. http://dx.doi.org/10.1080/00986448408911118

Avdeef, A., \& Tsinman, O. (2008). Miniaturized rotating disk intrinsic dissolution rate measurement: Effects of buffer capacity in comparisons to traditional wood's apparatus. Pharmaceutical Research, 25(11), 2613- 
2627. http://dx.doi.org/10.1007/s11095-008-9679-z

Bandyopadhyay, P. (1986). Review-Mean flow in turbulent boundary layers disturbed to alter skin friction. Journal of Fluids Engineering, 108(2), 127-140

Bari, H. A., \& Faraj, E. (2015). Studying the Interaction between a New Mixture in Enhancing Drag Reduction Efficiency. International Journal of Chemical Engineering and Applications, 6(4), 277-280. http://dx.doi.org/10.7763/IJCEA.2015.V6.496

Bari, H. A., Yousif, Z., \& Akindoyo, E. O. (2015). Enhancement of additives polymeric drag resistance to degradation. Journal of Purity, Utility Reaction and Environment, 4(2), 48-55.

Baron, A., Quadrio, M., \& Vigevano, L. (1993). On the boundary layer/riblets interaction mechanisms and the prediction of turbulent drag reduction. International Journal of Heat and Fluid Flow, 14(4), 324-332. http://dx.doi.org/10.1016/0142-727X(93)90005-8

Baucke, F. G., Landolt, D., \& Tobias1, C. W. (1968). Rotating Disk System for the Study of Metal Deposition from Nonaqueous Solvents. Review of Scientific Instruments, 39(11), 1753. http://dx.doi.org/10.1063/1.1683222

Bazanini, G., Bressan, J. D., \& Klemz, M. A. (2008). Cavitation Erosion Wear of Metallic Specimens Using the New Compact Rotating Disk Device. Thermal Engineering, 7(1), 31-36.

Bernardez, L. A. (2008a). Dissolution of polycyclic aromatic hydrocarbons from a non-aqueous phase liquid into a surfactant solution using a rotating disk apparatus. Colloids Surf A Physicochem Enginering, 320, 175182. http://dx.doi.org/10.1016/j.colsurfa.2008.01.044

Bernardez, L. A. (2008b). Investigation on the locus of solubilization of polycyclic aromatic hydrocarbons in non-ionic surfactant micelles with 1H NMR spectroscopy. Colloids and Surf A Physicochem Eng Asp, 324(1-3), 71-78. http://dx.doi.org/10.1016/j.colsurfa.2008.03.027

Bernardez, L. A. (2009). A rotating disk apparatus for assessing the biodegradation of polycyclic aromatic hydrocarbons transferring from a non-aqueous phase liquid to solutions of surfactant Brij 35. Bioprocess and Biosystems Engineering, 32(3), 415-424. http://dx.doi.org/10.1007/s00449-008-0261-1

Bernardez, L. A., \& Ghoshal, S. (2004). Selective solubilization of PAHs from a multicomponent NAPL into nonionic surfactant micelles. Environ Sci Technol, 38, 5878-5887. http://dx.doi.org/10.1021/es0497429

Bernardez, L. A., \& Ghoshal, S. (2008). Solubilization kinetics for polycyclic aromatic hydrocarbons transferring from a non-aqueous phase liquid to non-ionic surfactant solutions. Journal of Colloid Interface Science, 320, 298-306. http://dx.doi.org/10.1016/j.jcis.2007.12.035

Bizotto, V. C., \& Sabadini, E. (2008). Poly (ethylene oxide) polyacrylamide. Which one is more efficient to promote drag reduction in aqueous solution and less degradable? Journal of Applied Polymer Science, 110(3), 1844-1850. http://dx.doi.org/10.1002/app.28803.

Boles, B. R., Thoendel, M., \& Singh, P. K. (2004). Self-generated diversity produces insurance effects in biofilm communities. Process National Academic Science USA, 101, 16630-16635.

Boles, B. R., Thoendel, M., \& Singh, P. K. (2005). Rhamnolipids mediate detachment of Pseudomonas aeruginosa from biofilms. Molecular Microbiology, 57, 1210-1223. http://dx.doi.org/10.1111/j.1365-2958.2005.04743.x

Boomer, D. R., Mccune, C. C., \& Fogler, H. S. (1972). Rotating Disk Apparatus for Reaction Rate Studies in Corrosive Liquid Environments. The Review of Scientific Instruments, 43(2), 225-229. http://dx.doi.org/10.1063/1.1685599

Brostow, W., Ertepinar, H., \& Singh, R. P. (1990). Flow of Dilute Polymer Solutions: Chain Conformations and Degradation of Drag Reducers. Macromolecules, 23, 5109-5118. http://dx.doi.org/10.1021/ma00226a013

Brostow, W., Lobland, H. E. H., Reddy, T., Singh, R. P., \& White, L. (2007). Lowering mechanical degradation of drag reducers in turbulent flow. Journal of Materials Research, 22(01), 56-60. http://dx.doi.org/10.1557/jmr.2007.0003

Burger, E. D., Munk, W. R., \& Wahl, H. A. (1982). Flow Increase in the Trans Alaska Pipeline Through Use of a Polymeric Drag-Reducing Additive. Journal of Petroleum Technology, 34(2), 377-386. http://dx.doi.org/10.2118/9419-PA

Burgess, K. S. D., Kable, J. W., \& Justice, J. B. (1999). Rotating Disk Electrode Voltammetry Applied to the 
Kinetics of Uptake and Efflux in Wild-Type and Mutant Catecholamine Transporters. Electroanalysis, 11(5), 337-343. http://dx.doi.org/10.1002/(SICI)1521-4109(199905)11:5.

Burns, J. R., \& Jachuck, R. J. (2005). Monitoring of CaCO3 Production on a Spinning Disc Reactor Using Conductivity Measurements. AIChE Journal, 51(5), 1497-1507. http://dx.doi.org/10.1002/aic.10414

Burns, J. R., Ramshaw, C., \& Jachuck, R. J. (2003). Measurement of liquid film thickness and the determination of spin-up radius on a rotating disc using an electrical resistance technique. Chem. Engng. Sci., 58, 2245 2253. http://dx.doi.org/10.1016/S0009-2509(03)00091-5

Cadot, O., Bonn, D., \& Douady, S. (1998). Turbulent drag reduction in a closed flow system: Boundary layer versus bulk effects. Physics of Fluids, 10(2), 426. http://dx.doi.org/10.1063/1.869532

Cafiero, L. M., Baffi, G., Chianese, A., \& Jachuck, R. J. J. (2002). Process Intensification: Precipitation of Barium Sulfate Using a Spinning Disk Reactor. Ind. Eng. Chem. Res., 41(21), 5240-5246. http://dx.doi.org/ 10.1021/ie010654w

Caprariis, B. D., Stoller, M., Chianese, A., \& Verdone, N. (2015). CFD Model of a Spinning Disk Reactor for Nanoparticle Production. Chemical Engineering Transactions, 43, 757-762. http://dx.doi.org/10.3303/CET1543127

Choi, H. J., \& Jhon, M. S. (1996). Polymer-Induced Turbulent Drag Reduction. Industrial \& Engineering Chemistry Research, 35(95), 2993-2998. http://dx.doi.org/10.1021/ie9507484

Choi, H. J., Kim, C. A., \& Jhon, M. S. (1999). Universal drag reduction characteristics of polyisobutylene in a rotating disk apparatus. Polymer, 40(16), 4527-4530. http://dx.doi.org/10.1016/S0032-3861(98)00869-6

Choi, H. J., Kim, C. A., Sohn, J., \& Jhon, M. S. (2000). An exponential decay function for polymer degradation in turbulent drag reduction. Polymer Degradation and Stability, 69(3), 341-346. http://dx.doi.org/10.1016/S0141-3910(00)00080-X

Choi, H. J., Kim, C. A., Sung, J. H., Kim, C. B., Chun, W., \& Jhon, M. S. (2000). Universal drag reduction characteristics of saline water-soluble poly (ethylene oxide) in a rotating disk apparatus. Colloid \& Polymer Science, 278(7), 701-705. http://dx.doi.org/10.1007/s003960000328

Choi, H. J., Lim, S. T., Lai, P. Y., \& Chan, C. K. (2002). Turbulent drag reduction and degradation of DNA. Physical Review Letters, 89(8), 088302. http://dx.doi.org/10.1103/PhysRevLett.89.088302

Dujmovich, T., \& Gallegos, A. (2005). Drag reducers improve throughput, cut costs. Offshore, 65(12), 1-4.

Forest, F., \& G.Grierson. (1931). No Title. Paper Trade. J, 92(22), 39-41.

Fredd, C. N., \& Fogler, H. S. (1998). The kinetics of calcite dissolution in acetic acid solutions. Chemical Engineering Science, 53(22), 3863-3874. http://dx.doi.org/10.1016/S0009-2509(98)00192-4

Gad-El-Hak, M. (1998). Compliant coatings: the simpler alternative. Experimental Thermal and Fluid Science, 16(1-2), 141-156. http://dx.doi.org/10.1016/S0894-1777(97)10006-1

Ge, W., Zhang, Y., \& Zakin, J. L. (2007). Surfactant turbulent drag reduction in an enclosed rotating disk apparatus. Experiments in Fluids, 42(3), 459-469. W. Ge, Y. Zhang, and J. L. Zakin, S. http://dx.doi.org/10.1007/s00348-007-0253-y

Gyr, A., \& Bewersdorff, H. W. (1995). Drag reduction of turbulent flows by additives. Fluid Mechanics and Its Applications, 32, 234. http://dx.doi.org/10.1007/978-94-017-1295-8

Hand, J. H., \& Williams, M. C. (1970). DNA and Structural Effects in Turbulent Drag Reduction. Nature, 227, 369-370. http://dx.doi.org/10.1038/227369a0

Hansen, B. W., \& Rasmussen, R. E. H. (1968). Cavitation Damage Experiments in a Rotating Disk Apparatus Especially with Regard to the Gas Content of Water. Journal of Ship Research, 12, 83-88.

Hentzer, M., Teitzel, G. M., Balzer, G. J., Heydorn, A., Molin, S., Givskov, M., \& Parsek, M. R. (2001). Alginate overproduction affects Pseudomonas aeruginosa biofilm structure and function. Journal of Bacteriology, 183, 5395-5401. http://dx.doi.org/10.1128/JB.183.18.5395-5401.2001

Hong, C. H., Choi, H. J., \& Kim, J. H. (2008). Rotating disk apparatus for polymer-induced turbulent drag reduction. Journal of Mechanical Science and Technology, 22(10), 1908-1913. http://dx.doi.org/10.1007/s12206-008-0731-z

Hong, C. H., Choi, H. J., Zhang, K., Renou, F., \& Grisel, M. (2015). Effect of salt on turbulent drag reduction of 
xanthan gum. Carbohydrate Polymers, 121, 342-347. http://dx.doi.org/10.1016/j.carbpol.2014.12.015

Hong, C. H., Zhang, K., Choi, H. J., \& Yoon, S. M. (2010). Mechanical degradation of polysaccharide guar gum under turbulent flow. Journal of Industrial and Engineering Chemistry, 16(2), 178-180. http://dx.doi.org/10.1016/j.jiec.2009.09.073

Hoyt, J. (1972). A Freeman Scholar Lecture: The Effect of Additives on Fluid Friction. Journal of Fluids Engineering, 94(2), 258-285. http://dx.doi.org/10.1115/1.3425401

Hoyt, J. W. (1975). An apparatus for drag reduction determination, in Symposium on Rheology. (A. W. Morris \& J. S. Wang, Eds.). New York: Am. Soc. Mech. Engrs.

Hwang, S. D., Kwon, H. G., \& Cho, H. H. (2008). Heat transfer with dimple/protrusion arrays in a rectangular duct with a low Reynolds number range. International Journal of Heat and Fluid Flow, 29(4), 916-926. http://dx.doi.org/10.1016/j.ijheatfluidflow.2008.01.004

Igimi, H., \& Carey, M. C. (1981). Cholesterol gallstone dissolution in bile: dissolution kinetics of crystalline (anhydrate and monohydrate) cholesterol with chenodeoxycholate, ursodeoxycholate, and their glycine and taurine conjugates. Journal of Lipid Research, 22(2), 254-270.

Imayama, S., Alfredsson, P. H., \& Lingwood, R. J. (2011). An experimental study of laminar-turbulent transition of a rotating-disk flow to cite this version : EUROMECH Colloquium, 525, 21-23.

Iwai, Y., \& Okada, Y. (1987). Cavitation Erosion Induced by Rotating Disk Apparatus. In Lecture Note of the Fifth Cavitation Symposium in Japan (pp. 93-100).

Jafargholinejad, S., Pishevar, a., \& Sadeghy, K. (2011). On the use of rotating-disk geometry for evaluating the drag-reducing efficiency of polymeric and surfactant additives. Journal of Applied Fluid Mechanics, 4(3), $1-5$.

Jesusa, E. C., Santiagoa, D., Casillasb, G., Mayoralc, A., Magenc, C., José-Yacamanb, M., ... Cabrera, C. R. (2012). Platinum Electrodeposition on Unsupported Single Wall Carbon Nanotubes and Its Application as

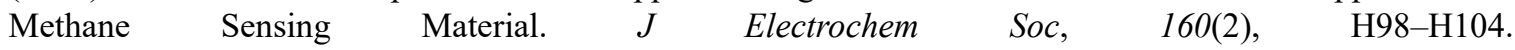
http://dx.doi.org/10.1016/j.biotechadv.2011.08.021.Secreted

Jhon, M. S., Sekhon, G., \& Armstrong, R. (1987). The response of polymer molecules in a flow. Advances in Chemical Physics, 66, 153-211. http://dx.doi.org/10.1002/9780470142929.ch2

Jinno, J., Oh, D. M., Crison, J. R., \& Amidon, G. L. (2000). Dissolution of ionizable water-insoluble drugs: The combined effect of $\mathrm{pH}$ and surfactant. Journal of Pharmaceutical Sciences, 89, 268-274. http://dx.doi.org/10.1002/ (SICI)1520-6017(200002)89:2<268::AID-JPS14>3.0.CO;2-F

Jorge, E. O., Neto, M. M. M., \& Rocha, M. M. (2007). A mercury-free electrochemical sensor for the determination of thallium(I) based on the rotating-disc bismuth film electrode. Talanta, 72(4), 1392-1399. http://dx.doi.org/10.1016/j.talanta.2007.01.047

Jung, W. (1992). Suppression of turbulence in wall bounded flows by high frequency spanwise oscillations. Physics of Fluids A: Fluid ..., 4(8), 1605-1607. http://dx.doi.org/10.1063/1.858381

Kalashnikov, V. N. (1998). Dynamical similarity and dimensionless relations for turbulent drag reduction by polymer additives. Journal of Non-Newtonian Fluid Mechanics, 75(2-3), 209-230. http://dx.doi.org/10.1016/S0377-0257(97)00093-1

Kim, C. A., Choi, H. J., Kim, C. B., \& Jhon, M. S. (1998). Drag reduction characteristics of polysaccharide xanthan gum. Macromolecular Rapid Communications, 19(8), 419-422. http://dx.doi.org/10.1002/marc.1998.030190804

Kim, C. A., Jo, D. S., Choi, H. J., Kim, C. B., \& Jhon, M. S. (2000). A high-precision rotating disk apparatus for drag reduction characterization. Polymer Testing, 20(1), 43-48. http://dx.doi.org/10.1016/S0142-9418(99)00077-X

Kim, C. A., Lee, K., Choi, H. J., Kim, C. B., Kim, K. Y., \& Jhon, M. S. (1997). Universal characteristics of drag reducing polyisobutylene in kerosene. Journal of Macromolecular Science Pure and Applied Chemistry, A34, 705-711. http://dx.doi.org/10.1080/10601329708014996

Kim, C. A., Lim, S. T., Choi, H. J., Sohn, J. I., \& Jhon, M. S. (2002). Characterization of drag reducing guar gum in a rotating disk flow. Journal of Applied Polymer Science, 83(13), 2938-2944. http://dx.doi.org/10.1002/app.10300 
Kim, C. A., Sung, J. H., Choi, H. J., Kim, C. B., Chun, W., \& Jhon, M. S. (1999). Drag Reduction and Mechanical Degradation of Poly (ethylene oxide) in Seawater. Journal of Chemical Engineering of Japan, 32(6), 803-811. http://dx.doi.org/10.1252/jcej.32.803

Kim, C., Kim, J., Lee, K., Choi, H., \& Jhon, M. (2000). Mechanical degradation of dilute polymer solutions under turbulent flow. Polymer, 41(21), 7611-7615. http://dx.doi.org/10.1016/S0032-3861(00)00135-X

Kim, J. T., Kim, C. A., Zhang, K., Jang, C. H., \& Choi, H. J. (2011). Effect of polymer-surfactant interaction on its turbulent drag reduction. Colloids and Surfaces A: Physicochemical and Engineering Aspects, 391(1-3), 125-129. http://dx.doi.org/10.1016/j.colsurfa.2011.04.018

Korzhova, V. N. (2009). Motion Analysis of Fluid Flow in a Spinning Disk Reactor.

Kramer, M. O. (1960). Boundary layer stabilization by distributed damping. Journal of the American Society for Naval Engineers, 72(1), 25-34. http://dx.doi.org/10.2514/8.8380

Krueger, C. W., Patnaik, S., Wang, C. A., \& Flytzani-Stephanopoulos, M. (1996). CH3I vapor etching of GaAs in a vertical rotating-disk reactor. Journal of Crystal Growth, 169(1), 51-60. http://dx.doi.org/10.1016/0022-0248(96)00278-3

Lee, K. H., Zhang, K., \& Choi, H. J. (2010). Time dependence of turbulent drag reduction efficiency of polyisobutylene in kerosene. Journal of Industrial and Engineering Chemistry, 16(4), 499-502. http://dx.doi.org/10.1016/j.jiec.2010.03.027

Lee, K., Kim, C. A., Lim, S. T., Kwon, D. H., Choi, H. J., \& Jhon, M. S. (2002). Mechanical degradation of polyisobutylene under turbulent flow. Colloid and Polymer Science, 280(8), 779-782. http://dx.doi.org/10.1007/s00396-002-0690-3

Li, S., Doyle, P., Metz, S., Royce, A. E., \& Serajuddin, A. T. M. (2005). Effect of chloride ion on dissolution of different salt forms of haloperidol, a model basic drug. Journal of Pharmaceutical Sciences, 94, 2224-2231. http://dx.doi.org/10.1002/jps.20440

Li, S., Wong, M., Sethia, S. S., Almoazen, H., Joshi, Y. M., \& Serajuddin, A. (2005). Investigation of solubility of a free base and two different salt forms as a function of $\mathrm{pH}$. Pharmaceutical Research, 4, 628-635. http://dx.doi.org/10.1007/s11095-005-2504-z

Lichtman, J. Z., \& Weingram, E. R. (1964). The Use of a Rotating Disk Apparatus in Determining Cavitation Erosion Resistance of Materials. In ASME Symp. on Cavitation Research Facilities and Techniques (pp. 185-196).

Lightman, J. Z., Kallas, D. H., Chatten, C. K., \& Cochran, E. P. (1961). Cavitation Erosion of Structural Materials and Coatings. Corrosion, 17, 497t-505t. http://dx.doi.org/abs/10.5006/0010-9312-17.10.119

Lim, S. T., Choi, H. J., Biswal, D., \& Singh, R. P. (2004). Turbulent drag reduction characteristics of amylopectin and its derivative. E-Polymers, 4(1), 751-760. http://dx.doi.org/10.1515/epoly.2004.4.1.751

Lim, S. T., Choi, H. J., Lee, S. Y., So, J. S., \& Chan, C. K. (2003). $\lambda$-DNA induced turbulent drag reduction and its characteristics. Macromolecules, 36(14), 5348-5354. http://dx.doi.org/10.1021/ma025964k

Lim, S. T., Hong, C. H., Choi, H. J., Lai, P.-Y., \& Chan, C. K. (2007). Polymer turbulent drag reduction near the theta point. Europhysics Letters (EPL), 80(5), 58003. http://dx.doi.org/10.1209/0295-5075/80/58003

Lim, S. T., Lee, K., Kim, C. A., Choit, H. J., Kim, J. G., \& Jhon, M. S. (2002). Turbulent Drag Reduction and Mechanical Degradation of Polyisobutylene in Kerosene. J. Ind. Eng. Chem., 8(4), 365-369.

Lim, S. T., Park, S. J., Chan, C. K., \& Choi, H. J. (2005). Turbulent drag reduction characteristics induced by calf-thymus DNA. Physica A: Statistical Mechanics and Its Applications, 350(1), 84-88. http://dx.doi.org/10.1016/j.physa.2004.11.034

Lin, H. Y., Chen, C. T., \& Huang, C. T. (2004). Use of merocyanine 540 for photodynamic inactivation of Staphylococcus aureus planktonic and biofilm cells. Applied and Environmental Microbiology, 70, 6453 6458. http://dx.doi.org/10.1128/AEM.70.11.6453-6458

Litt, M., \& Serad, G. (1964). Chemical reactions on a rotating disk. Chemical Engineering Science, 19(11), 867884. http://dx.doi.org/10.1016/0009-2509(64)85065-X

Little, R. C., Patterson, R. L., \& Ting, R. Y. (1976). Characterization of the drag reducing properties of poly(ethylene oxide) and poly(acrylamide) solutions in external flows. Journal of Chemical and Engineering Data, 21(3), 281-283. http://dx.doi.org/10.1021/je60070a025 
Lund, K., \& Foglers, H. S. (1975). Acidization-II. The Dissolution of Calcite in Hydrochloric Acid. Chemical Engineering Science, 30, 825-835. http://dx.doi.org/10.1016/0009-2509(75)80047-9

Lund, K., Fogler, H. S., \& Mccune, C. C. (1973). Acidization-I. The dissolution of dolomite in hydrochloric acid. Chemical Engineering ScienceEngineering Science, 28, 691-700. http://dx.doi.org/10.1016/0009-2509(77)80003-1

McBreen, J., O’Grady, W. E., \& Richter, R. (1984). A Rotating Disk Electrode Apparatus for the Study of Fuel Cell Reactions at Elevated Temperatures and Pressures. Journal of Electrochemical Society, 131(5), 12151216. http://dx.doi.org/10.1149/1.2115782

Mccormick, C. L., Heater, R. D., Morgan, S. E., \& Safieddine, A. M. (1990). Water-soluble copolymers. 30. Effects of molecular structure on drag reduction efficiency. Macromolecules, 23(8), 2124-2131. http://dx.doi.org/10.1021/ma00210a005

McCormick, C. L., Hester, R. D., Morgan, S. E., \& Safieddine, A. M. (1990). Water-soluble copolymers. 31. Effects of molecular parameters, solvation, and polymer associations on drag reduction performance. Macromolecules, 23(8), 2132-2139. http://dx.doi.org/10.1021/ma00210a006

Mccormick, M. E., \& Bhattacharyya, R. (1973). Drag reduction of a submersible hull by electrolysis. Naval Engineers Journal, 85(2), 11-16. http://dx.doi.org/10.1111/j.1559-3584.1973.tb04788.x

McElvain, J. S., \& Schenk, J. O. (1992). A multisubstrate mechanism of striatal dopamine uptake and its inhibition by cocaine. Biochemical Pharmacology, 43(10), 2189-2199. http://dx.doi.org/10.1016/0006-2952(92)90178-L

McNamara, D. P., \& Amidon, G. L. (1986). Dissolution of acidic and basic compounds from the rotating disk: influence of convective diffusion and reaction. Journal of Pharmaceutical Sciences, 75, 858-868. http://dx.doi.org/10.1002/jps.2600750907

McNamara, D. P., \& Amidon, G. L. (1988). Reaction plane approach for estimating the effects of buffers on the dissolution rate of acidic drugs. Journal of Pharmaceutical Sciences, 77, 511-517. http://dx.doi.org/10.1002/ jps.2600770610

Meiergerd, S. M., Mcelvaint, J. S., \& H, J. O. S. (1994). Effects Of Cocaine And Repeated Cocaine Followed By $\begin{array}{llll}\text { Withdrawal. Biochemical } & \text { Pharmacology, }\end{array}$ http://dx.doi.org/10.1016/0006-2952(94)90541-X

Meiergerd, S., \& Schenk, J. (1994). Kinetic evaluation of the commonality between the site(s) of action of cocaine and some other structurally similar and dissimilar inhibitors of the striatal transporter for dopamine. Journal of Neurochemistry, 63(5), 1683-1692. http://dx.doi.org/10.1046/j.1471-4159.1994.63051683.x

Meiergerd, S., Hooks, S., \& Schenk, J. (1994). The striatal transporter for dopamine in the rat may be kinetically up-regulated following 3 weeks of withdrawal from cocaine self-administration. Journal of Neurochemistry, 63(4), 1277-1281. http://dx.doi.org/10.1046/j.1471-4159.1994.63041277.x

Mooney, K. G., Mintun, M. A., Himmelstein, K. J., \& Stella, V. J. (1981a). Dissolution kinetics of carboxylic acids I: effect of $\mathrm{pH}$ under unbuffered conditions. Journal of Pharmaceutical Sciences, 70, 13-22. http://dx.doi.org/10. 1002/jps.2600700103

Mooney, K. G., Mintun, M. A., Himmelstein, K. J., \& Stella, V. J. (1981b). Dissolution kinetics of carboxylic acids II: effects of buffers. Journal of Pharmaceutical Sciences, 70, 22-32. http://dx.doi.org/10.1002/jps.2600700104

Moussa, T., \& Tiu, C. (1994). Factors affecting polymer degradation in turbulent pipe flow. Chemical Engineering Science, 49(10), 1681-1692. http://dx.doi.org/10.1016/0009-2509(93)E0029-C

Mumick, P. S., Welch, P. M., Salazar, L. C., \& McCormick, C. L. (1994). Water-soluble copolymers. 56. Structure and solvation effects of polyampholytes in drag reduction. Macromolecules, 27(2), 323-331. http://dx.doi.org/10.1021/ma00080a003

Mysels, K. J. (1949). Flow of thickened fluids. United State Patent.

Nakken, T., Tande, M., \& Elgsaeter, A. (2001). Measurements of polymer induced drag reduction and polymer scission in Taylor flow using standard double-gap sample holders with axial symmetry. Journal of Non-Newtonian Fluid Mechanics, 97(1), 1-12. http://dx.doi.org/10.1016/S0377-0257(00)00195-6

Neopane, H. P., Sujakhu, S., Shrestha, S., Subedi, K., \& Basnet, A. (2012). Study of sediment erosion in 
hydraulic turbine using rotating disc apparatus. 2nd International Conference on the Developments in Renewable Energy Technology (ICDRET 2012), 1-4

Panella, R. A., Ydstie, B. E., \& Prieve, D. C. (2011). Rapid deposition of titania nanoparticles on tin oxide for dye solar cell anodes using fluid mechanics and eletrokinetics. Conference Record of the IEEE Photovoltaic Specialists Conference, 001182-001186. http://dx.doi.org/10.1109/PVSC.2011.6186167

Patnaik, S., Brown, R. A., \& Wang, C. A. (1989). Hydrodynamic dispersion in rotating-disk omvpe reactors: Numerical simulation and experimental measurements. Journal of Crystal Growth, 96(1), 153-174. http://dx.doi.org/10.1016/0022-0248(89)90285-6

Peyser, P., \& Little, R. C. (1971). The drag reduction of dilute polymer solutions as a function of solvent power, viscosity, and temperature. Journal of Applied Polymer Science, 15(11), 2623-2637. http://dx.doi.org/10.1002/app.1971.070151102

Pitts, B., Willse, A., McFeters, G. A., Hamilton, M. A., Zelver, N., \& Stewart, P. S. (2001). A repeatable laboratory method for testing the efficacy of biocides against toilet bowl biofilms. Journal of Applied Microbiology, 91, 110-117. http://dx.doi.org/10.1046/j.1365-2672.2001.01342.x

Popov, B. N. (1993). Galvanostatic Pulse and Pulse Reverse Plating of Nickel-Iron Alloys from Electrolytes Containing Organic Compounds on a Rotating Disk Electrode. Journal of the Electrochemical Society, 140(5), 1321. http://dx.doi.org/10.1149/1.2220978

Povlock, S. L., \& Schenk, J. O. (1997). A multisubstrate kinetic mechanism of dopamine transport in the nucleus accumbens and its inhibition by cocaine. Journal Of Neurochemistry, 69(3), 1093. http://dx.doi.org/10.1046/j.1471-4159.1997.69031093.x

Rao, P. V., \& Buckley, D. H. (1987). Unified Empirical Relations For Cavitation And Liquid Impingement Erosion Processes. Wear, 120, 253-288. http://dx.doi.org/10.1016/0043-1648(87)90022-6

Rao, P. V., \& Rao, B. C. S. (1981). Some Erosion Studies and Scale Effects with Rotating Disk Device. In ASME Symp. on Cavitation Erosion in Fluid Systems (pp. 119-131).

Rao, P. V., Rao, B. C. S., \& Rao, N. S. L. (1980). Erosion and Cavity Characteristics in Rotating Components. Journal of Testing and Evaluation, 8, 127-142. http://dx.doi.org/10.1520/JTE10609J

Rehage, H., Wunderlich, I., \& Hoffmann, H. (1986). Shear induced phase transitions in dilute aqueous surfactant solutions. Polymers as Colloid Systems, 59, 51-59. Retrieved from http://www.springerlink.com/index/wr16h35610243373.pdf

Robertson, I. G., \& Weatherley, L. R. (2004). Mixing and Reaction in a Novel Spinning Disk Reactor. In 32nd Australasian Chemical Engineering Conference: Sustainable Processes (pp. 2-7).

Rodriguez, F., \& Winding, C. C. (1959). Mechanical Degradation of Polyisobutylene Solutions. Ind. Eng. Chem., 51(10), 1281-1284. http://dx.doi.org/10.1021/ie50598a034

Rodríguez-Calero, G. G., Rivera, H., Tryk, D. A., Scibioh, M. A., \& Cabrera, C. R. (2010). Platinum Electrodeposition at High Surface Area Carbon Vulcan-XC-72R Material Using a Rotating Disk-Slurry Electrode Technique. Journal of Electrochemical Society, 157(12), F189-F195. http://dx.doi.org/10.1149/1.3489948

Schlichting, J. K. H. (1979). Boundary - Layer Theory (7th ed.). New York: McGraw-Hill.

Schwartz, K., Stephenson, R., Hernandez, M., Jambang, N., \& Boles, B. R. (2010). The use of drip flow and rotating disk reactors for Staphylococcus aureus biofilm analysis. Journal of Visualized Experiments : JoVE, 46, 1-5. http://dx.doi.org/10.3791/2470

Serajuddin, A. T. M., \& Jarowski, C. I. (1984). pH-solubility profile of papaverine hydrochloride and its relationship to the dissolution rate of sustained-release pellets. Journal of Pharmaceutical Sciences, 73, 1203-1208. http://dx.doi.org/10.1002/jps.2600730905

Serajuddin, A. T. M., \& Jarowski, C. I. (1985). Effect of diffusion layer $\mathrm{pH}$ and solubility on the dissolution rate of pharmaceutical bases and their hydrochloride salts I: Phenazopyridine. Journal of Pharmaceutical Sciences, 74, 142-147. http://dx.doi.org/10.1002/jps.2600740208

Sheng, J. J., Kasim, N. A., Chandrasekharan, R., \& L., G. A. (2006). Solubilization and dissolution of insoluble weak acid, ketoprofen: effect of $\mathrm{pH}$ combined with surfactant. European Journal of Pharmaceutical Sciences, 29, 306-314. http://dx.doi.org/10.1016/j.ejps.2006.06.006 
Shikata, T., Hirata, H., \& Kotaka, T. (1988). Micelle formation of detergent molecules in aqueous media. 2. Role of free salicylate ions on viscoelastic properties of aqueous cetyltrimethylammonium bromide-sodium salicylate solutions. Langmuir, 4(2), 354-359. http://dx.doi.org/10.1021/la00080a019

Shima, A., Tomaru, H., Ihara, A., \& Miura, N. (1992). Cavitation damage study with a rotating disk at the high peripheral velocities. Journal of Hydraulic Research, 30(4), 521-538. http://dx.doi.org/10.1080/00221689209498898

Sohn, J. I., Kim, C. A., Choi, H. J., \& Jhon, M. S. (2001). Drag-reduction effectiveness of xanthan gum in a rotating disk apparatus. Carbohydrate Polymers, 45(1), 61-68. http://dx.doi.org/10.1016/S0144-8617(00)00232-0

Southard, M. Z., Green, D. W., Stella, V. J., \& Himmelstein, K. J. (1992). Dissolution of ionizable drugs into unbuffered solution: a comprehensive model for mass transport and reaction in the rotating disk geometry. Pharmaceutical Research, 9, 58-69. http://dx.doi.org/10.1023/ A:1018979727118.

Steller, K., Krzyztofowicz, T., \& Reymann, Z. (1974). Effects of Cavitation on Materials in Field and Laboratory Conditions, Erosion, Wear, and Interfaces with Corrosion. In STP567, ASTM, Philadelphia (pp. 152-170).

Stojanovic, R. S., Kubacki, J. F., Dorin, R., \& Frazer, E. J. (1995). Development of a rotating ring-disc electrode for high temperature studies in cryolite-based melts. Journal of Applied Electrochemistry, 25(5), 456-461. http://dx.doi.org/10.1007/BF00260688

Stoller, M., Miranda, L., \& Chianese, A. (2009). Optimal feed location in a rotating disk reactor for the production of TiO2 nanoparticles. Chemical Engineering Transactions, 17, 993-998.

Stollera, M., Mesciab, M., Peronib, V. C., \& Chianesea, A. (2007). Production of Nanoparticles of Titanium Dioxide by Using a Spinning Disc Reactor. Chemical Engineering Transactions, 11(1), 71-76. http://dx.doi.org/10.1016/j.cej.2014.07.042

Sunarso, J., Torriero, A. A. J., Zhou, W., Howlett, P. C., \& Forsyth, M. (2012). Oxygen reduction reaction activity of La-based perovskite oxides in alkaline medium: A thin-film rotating ring-disk electrode study. Journal of Physical Chemistry C, 116(9), 5827-5834. http://dx.doi.org/10.1021/jp211946n

Sung, J. H., Kim, C. A., Choi, H. J., Hur, B. K., Kim, J. G., \& Jhon, M. S. (2004). Turbulent Drag Reduction Efficiency and Mechanical Degradation of Poly (Acrylamide). Journal of Macromolecular Science, Part B, 43(2), 507-518. http://dx.doi.org/10.1081/MB-120029784

Sung, J. H., Lim, S. T., Kim, C. A., Chung, H., \& Choi, H. J. (2004). Mechanical degradation kinetics of poly (ethylene oxide) in a turbulent flow. Korea-Australia Rheology Journal, 16(2), 57-62. http://www.cheric.org/article/442210

Tabor, M., \& Gennes, P. G. D. (2007). A Cascade Theory of Drag Reduction. Europhysics Letters (EPL), 2(7), 519-522. http://dx.doi.org/10.1209/0295-5075/2/7/005

Tanguy, J., Deniau, G., Zalczer, G., \& Lécayon, G. (1996). Cathodic electropolymerization of methacrylonitrile studied in situ by quartz crystal microbalance, cyclic voltammetry, and impedance spectroscopy. Journal of Electroanalytical Chemistry, 417(1-2), 175-184. http://dx.doi.org/10.1016/S0022-0728(96)04743-2

Toms, B. (1949). Detection of a wall effect in laminar flow of solutions of a linear polymer. Journal of Colloid Science, 4(5), 511-521. http://dx.doi.org/10.1016/0095-8522(49)90047-1

Tong, P., Goldburg, W. I., Huang, J. S., \& Witten, T. A. (1990). Anisotropy in turbulent drag reduction. Physical Review Letters, 65(22), 2780. http://dx.doi.org/http://dx.doi.org/10.1103/PhysRevLett.65.2780

Tseng, Y., Patel, M., \& Zhao, Y. (2014). Determination of Intrinsic Dissolution Rate Using Miniaturized Rotating and Stationary Disk Systems. Dissolution Technologies, 21(2), 24-29. http://dx.doi.org/10.14227/DT210214P24

Uribe-Godínez, J., Castellanos, R. H., Borja-Arco, E., Altamirano-Gutiérrez, a., \& Jiménez-Sandoval, O. (2008). Novel osmium-based electrocatalysts for oxygen reduction and hydrogen oxidation in acid conditions. Journal of Power Sources, 177(2), 286-295. http://dx.doi.org/10.1016/j.jpowsour.2007.11.063

Vatankhah, C., Jafargholinejad, S., \& Mozaffarinia, R. (2011). Experimental Investigation on Drag Reduction Performance of Two Kind of Polymeric Coatings with Rotating Disk Apparatus. Australian Journal of Basic and Applied Sciences, 5(4), 143-148.

Viel, P., Bureau, C., Deniau, G., Zalczer, G., \& Lecayon, G. (1999). Electropolymerization of methacrylonitrile 
on a rotating disk electrode at high spinning rate. Journal of Electroanalytical Chemistry, 470(1), 14-22. http://dx.doi.org/10.1016/S0022-0728(99)00202-8

Virk, P. (1975). Drag reduction by collapsed and extended polyelectrolytes. Nature, 253, 109-110. http://dx.doi.org/10.1038/253109a0

Watanabe, K., \& Ogata, S. (1998). Drag reduction for a rotating disk with highly water - repellent wall. JSME International Journal, Series B, 41(3), 556-560. http://dx.doi.org/10.1248/cpb.37.3229

Watanabe, K., Budiarso, Ogata, S., \& Uemura, K. (2005). Drag Reduction of an Enclosed Rotating Disk with Fine Spiral Grooves. Transactions of the Japan Society of Mechanical Engineers Series B, 71(712), 28492855. http://dx.doi.org/10.1299/kikaib.71.2849

Wood, G. M., Kundsen, L. K., \& Hammitt, F. G. (1967). Cavitation Damage Studies with Rotating Disk in Water. Journal of Basic Engineering ASME, 89, 98-110. http://dx.doi.org/10.1115/1.3609577

Wu, S. J., Ouyang, K., \& Shiah, S. W. (2008). Robust design of microbubble drag reduction in a channel flow using the Taguchi method. Ocean Engineering, 35(8-9), 856-863. http://dx.doi.org/10.1016/j.oceaneng.2008.01.022

Yang, K. S., Choi, H. J., Kim, C. B., \& Jhon, M. S. (1991). A study of drag reduction by polymer additives in rotating disk geometry. Korean $J$. Rheol, 3(1), 76.

Ying, R. Y. (1988). Electrodeposition of Copper-Nickel Alloys from Citrate Solutions on a Rotating Disk Electrode. Journal of The Electrochemical Society, 135(12), 2964. http://dx.doi.org/10.1149/1.2095470

Yu, L. X., Carlin, A. S., Amidon, G. L., \& Hussain, A. S. (2004). Feasibility studies of utilizing disk intrinsic dissolution rate to classify drugs. International Journal of Pharmaceutics, 270, 221-227. http://dx.doi.org/10.1016/j. ijpharm.2003.10.016

Zhang, K., Choi, H. J., \& Jang, C. H. (2011). Turbulent drag reduction characteristics of poly(acrylamide-co-acrylic acid) in a rotating disk apparatus. Colloid and Polymer Science, 289(17-18), 1821-1827. http://dx.doi.org/10.1007/s00396-011-2502-0

\section{Copyrights}

Copyright for this article is retained by the author(s), with first publication rights granted to the journal.

This is an open-access article distributed under the terms and conditions of the Creative Commons Attribution license (http://creativecommons.org/licenses/by/3.0/). 